\title{
O STOMÁKHION DE ARQUIMEDES: TRADUÇÃO COM NOTAS E INTRODUÇÃO
}

\author{
Henrique Marins de Carvalho \\ Instituto Federal de Educação, Ciência e Tecnologia de São Paulo - IFSP \\ Jamil Ibrahim Iskandar \\ Universidade Federal de São Paulo - Unifesp - Brasil \\ João F. N. B. Cortese \\ Universidade de São Paulo - USP - Brasil \\ Tiago Tranjan \\ Universidade Federal de São Paulo - Unifesp - Brasil \\ Vicente A. de Arruda Sampaio \\ Faculdade de São Bento - Brasil \\ (aceito para publicação em julho de 2021)
}

\begin{abstract}
Resumo
O artigo apresenta uma tradução com notas dos fragmentos do Stomákhion, um tratado matemático de Arquimedes sobre um jogo de montar peças bastante conhecido no mediterrâneo antigo. Foram vertidos para o português todos os textos supérstites em grego e em tradução árabe. Antecedendo a tradução, há uma introdução que traz informações relevantes a respeito da composição e da transmissão do texto, bem como reflexões acerca do significado matemático da obra. As notas oferecem esclarecimentos de caráter histórico, filológico e matemático.
\end{abstract}

Palavras-chave: História da matemática, Matemática grega, Arquimedes, Stomákhion, Tradução. 


\title{
[ARCHIMEDES' STOMÁKHION: A Portuguese Translation With Notes And A Brief Introductory Essay]
}

\begin{abstract}
The paper presents a translation with notes of the fragments of the Stomákhion, a mathematical treatise by Archimedes on a game of assembling pieces well known in the ancient Mediterranean. All the remaining texts in Greek and Arabic translations were translated into Portuguese. An introduction precedes the translation, providing relevant information about the composition and transmission of the text, as well as reflections about the mathematical meaning of the work. The notes offer historical, philological, and mathematical clarifications.
\end{abstract}

Keywords: History of Mathematics, Greek mathematics, Archimedes, Stomachion, Translation.

\section{Introdução}

O artigo apresenta uma tradução com notas dos fragmentos do Stomákhion ${ }^{1}$, um tratado matemático de Arquimedes sobre um jogo de montar peças bastante conhecido no mediterrâneo antigo. Foram vertidos para o português todos os textos supérstites em grego e em tradução árabe. Antecedendo a tradução, há uma introdução que traz informações relevantes a respeito da composição e da transmissão do texto, bem como reflexões acerca do significado matemático da obra. As notas oferecem esclarecimentos de caráter histórico, filológico e matemático.

\subsection{Stomákhion: o jogo}

Durante toda a Antiguidade, desde bem antes de Arquimedes, o stomákhion era um jogo comum na bacia do Mediterrâneo ${ }^{2}$. Quatorze peças, obtidas a partir da divisão de um quadrado (ver diagrama abaixo) deviam ser recombinadas de forma a compor figuras diversas, tais como um elefante ou um guerreiro. É o que conta, por exemplo, o poeta romano Ausônio (séc. IV d.C.) em carta dirigida a seu amigo Paulo, na qual faz uma comparação entre o stomákhion e o centão, técnica de composição poética que consiste numa colagem de versos ou pedaços de versos conhecidos do público e com métrica variada.

\footnotetext{
${ }^{1}$ Este artigo segue as normas de transliteração do grego sugeridas pela Sociedade Brasileira de Estudos Clássicos (SBEC).

${ }^{2}$ Ver NETZ, ACERBI \& WILSON, 2004, pp. 69-70.
}

RBHM, Vol. 21, n 42, pp. 14-51, 2021 


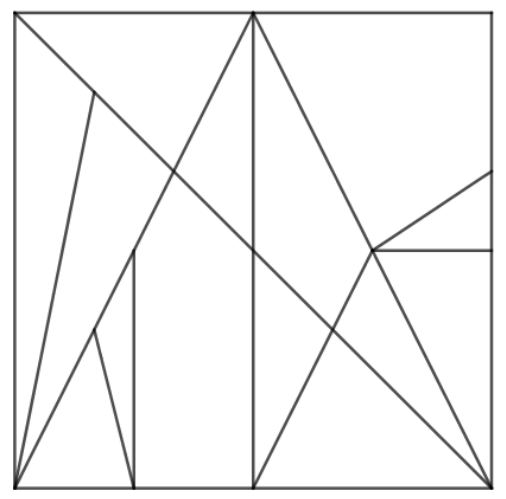

As peças do stomákhion

“... vou expor o que é um centão. É um poema constituído por uma variedade de passagens e sentidos diferentes, de tal forma que, ou duas meias linhas são unidas para formar uma, ou uma linha e a metade da seguinte com outra metade. Tu podes dizer que o centão é semelhante ao jogo que os gregos chamaram de ostomáchion. Umas pecinhas de osso, quatorze no total, que têm formas geométricas. Algumas são triângulos equiláteros, algumas têm lados de vários comprimentos, algumas são simétricas, algumas têm ângulos retos e outras oblíquos. Ao ajustar essas peças de várias maneiras, são produzidas inúmeras formas: um elefante monstruoso, um javali brutal, um ganso em vôo e um gladiador em armadura, um caçador de tocaia, um cão latindo, e ainda uma torre e um cântaro e inúmeras outras coisas do mesmo tipo, cuja variedade depende da habilidade do jogador." 3

\footnotetext{
3 “... cento quid sit, absouam. uariis de locis sensibusque diuersis quaedam carminis structura solidatur, in unum uersum ut coeant aut caesi duo aut unus et sequens <medius> cum medio. simile ut dicas ludicro, quod Graeci ostomachion uocauere. ossicula ea sunt : ad summam quattuordecim figuras geometricas habent. sunt enim aequaliter triquetra uel extentis lineis uel <eiusdem > frontis, <uel rectis > angulis uel obliquis : isoscele ipsi uel isopleura uocant, orthogonia quoque et scalena. harum uerticularum uariis coagmen tis simulantur species mille formarum : helephantus belua aut aper bestia, anser uolans et mirmillo in armis, subsidens uenator et latrans canis, quin et turris et cantharus et alia huiusmodi innumerabilium figurarum, quae alius alio scientius uariegant." O texto latino em que se baseia a tradução apresentada foi extraído da edição Loeb (AUSONIUS, 1919, pp. 372, 374). Note-se que nele o jogo é chamado de ostomáchion, um nome composto de ostéon (ỏotźov) = osso e mákhe $(\mu \alpha ́ x \eta)=$ luta, batalha, com o significado de batalha de ossos. Giuseppe Morelli, que produziu o mais amplo estudo filológico sobre as referências literárias antigas ao stomákhion, cita a mesma passagem de Ausônio, mas a partir de outra fonte que considera mais fidedigna, na qual o nome do jogo aparece em letras gregas e com outro nome: otopớxıv (stomákhion). Contra a suposição de que o jogo tivesse também o nome de ostomáchion, Morelli argumenta que o único nome do jogo é mesmo stomákhion e observa que o designativo ostomáchion é encontrado apenas em uma das fontes de Ausônio, atribuindo seu emprego, tal como Heiberg (1907, p. 241), a um lapso de transmissão decorrente da "restauração etimológica sugerida pelo contexto". (MORELLI, 2009, pp. 191-193). Sobre o nome do tratado de Arquimedes, ver também, 1.3. Para uma conjectura bem precisa das regras do jogo, ver MORELLI, 2009, p. 200.
} 
Mas curiosamente, com a exceção dos fragmentos da obra de Arquimedes, o jogo não é citado em qualquer documento da literatura árabe ou grega. Em contraste, há várias passagens da literatura latina nas quais ele é mencionado direta ou indiretamente. Numa delas, o gramático Élio Festo Aftônio o chama por um designativo que o associa diretamente ao matemático grego: “caixinha de Arquimedes” (loculus archimedius).

"Pois tal como há, quanto aos metros que devem ser conhecidos de início e emanam de nove protótipos, uma variedade interna multiforme e uma abundância vinda como que de um número limitado de 'sementes', do mesmo modo aquela caixinha de Arquimedes com catorze peças de marfim é apresentada, ora por peças quadradas, ora por peças triangulares, ora por ambas essas formas configuradas variadamente, qual um composto é produzido por certas partes graças a uma arte construtiva. Com efeito, tal como são configurados naquele número limitado e determinado de peças, por meio de uma forma agregada, ora um navio, ora uma espada, ora um arbusto ou qualquer outra coisa, do mesmo modo, por meio de um numero exato de metros, determinado desde o início e compreendido por dez protótipos, é gerada uma grande quantidade de tipos de versos." ${ }^{4}$

\subsection{Stomákhion: o tratado e sua transmissão}

A mesma palavra Stomákhion ${ }^{5}$ também serve de título a um tratado de Arquimedes do qual sobreviveram poucos e breves fragmentos. Nos limites do que foi possível auferir da pesquisa para a produção deste artigo, há somente 5 fontes: 4 manuscritos de um mesmo trecho em árabe ${ }^{6}$ e 1 palimpsesto encontrado e estudado no início do século XX (no tópico 2.2 são dadas mais informações sobre as fontes).

\footnotetext{
4 "ita enim metrorum, quae ex origine noscenda e prototypis novem profluunt, inter se varietas multiformis et de praefinito veluti quorundam seminum numero innumerabilis copia est, ut ille loculus archimedius e quattuordecim crustis eburneis, nunc quadratis, nunc triangulis, nunc ex utraque specie varie figuratis, velut quibusdam membris artis struendae causa compositus proditur. nam ut in illo praefinito ac determinato crustarum numero multiplici specie nunc navis, nunc gladius, nunc arbuscula et siqua alia figurantur, ita metrorum certo ex origine numero intra decem prototypa comprehenso multiplex admodum varietatis copia propagatur.” Tal passagem de Aftônio provém de seu prefácio a De metris III, onte trata dos metros poéticos mistos e entrelaçados (de coniunctis inter se et mixtis metris). Em SUTER, 1899, p. 494, essa passagem é falsamente atribuída a Mário Victorino. Com efeito, como apontou Franco Minonzio (2000), na maioria dos trabalhos sobre história da matemática, tanto nos mais antigos (sobretudo as influentes obras de Heiberg e Dijksterhuis) como nos nem tão antigos (como o léxico de Mugler, já na década de 1970), é comum que os tratados latinos de métrica poética estejam falsamente atribuídos a Atílio Fortunato e Mário Victorino (ver também MORELLI, 2009, p. 195).

${ }^{5}$ Neste artigo, escreveremos stomákhion, com minúscula, em referência ao jogo, e Stomákhion, em maiúscula, em referência ao tratado.

${ }^{6}$ Informações mais precisas sobre os manuscritos árabes podem ser encontradas em SUTER, 1899, pp. 493-494 (ver também 2.2). O trecho neles preservado descreve as divisões do quadrado que geram as figuras do jogo, por meio do que é possível, usando princípios da geometria euclidiana, obter a área de cada uma delas em relação à área total do quadrado.
}

RBHM, Vol. 21, n 42, pp. 14-51, 2021 
A descoberta desse palimpsesto remonta ao trabalho bibliográfico de Athanasios Papadopoulos-Kerameus (1856-1912), erudito radicado em Istambul e autor de um grande catálogo de manuscritos gregos guardados em igrejas e monastérios ortodoxos. Ao tomar conhecimento desse inventário, o célebre filólogo dinamarquês Johan Ludvig Heiberg (1854-1928), que já havia publicado em 1880 uma edição crítica da obra de Arquimedes, suspeitou que nele talvez pudesse encontrar mais textos do matemático de Siracusa. Tratou então de examinar vários dos documentos catalogados por Kerameus, até que em $1906 \mathrm{fez}$ sua grande descoberta: sob um eucológio (livro de orações medieval) descobriu centenas de páginas com escritos arquimedianos considerados perdidos, conforme relata em artigo publicado em 1907. E embora a tarefa de editar esses textos fosse grande e complexa, Heiberg logrou incorporá-los à sua nova edição das Obras completas poucos anos depois, em 1913 (ARQUIMEDES, 1910-15). O trecho referente ao Stomákhion estava contido nos folios 172 e 177 do palimpsesto. Tratava-se de um dos textos mais prejudicados pelas vicissitudes do tempo. De acordo com NETZ \& NOEL (2009 [2007]), a seção final do manuscrito, que iria até o fólio 185, foi inteiramente perdida e substituída por um suplemento de papel no século XVI.

Após o trabalho filológico de Heiberg, a relíquia ficou sob a custódia de um museu grego e posteriormente, à época da Primeira Guerra Mundial, foi adquirida de modo clandestino por um soldado francês. Durante longas décadas, o livro permaneceu como que esquecido na França, armazenado em condições bastante precárias, atacado por mofo e traças. Mas em 1998 veio a leilão e foi arrematado por um comprador anônimo, ao valor de 2 milhões de dólares, após acirrada disputa com o governo grego. O milionário que adquiriu o livro, guardou-o então no Walters Art Museum, em Baltimore (EUA), sob os cuidados de uma equipe de especialistas cujo objetivo era recuperar, pelo uso de modernas tecnologias de fotografia e de tratamento digital de imagens, todas as informações possíveis (NETZ \& NOEL, 2009 [2007]). Esse esforço minucioso de uma equipe multidisciplinar altamente qualificada foi ainda ajudado pela descoberta de fotos do livro que haviam sido produzidas pelo próprio Heiberg e que até então se julgavam perdidas. O texto grego traduzido neste artigo, cujo trabalho de edição foi liderado por Reviel Netz (NETZ, ACERBI \& WILSON, 2004), é fruto de todo esse empreendimento de recuperação material do palimpsesto. 


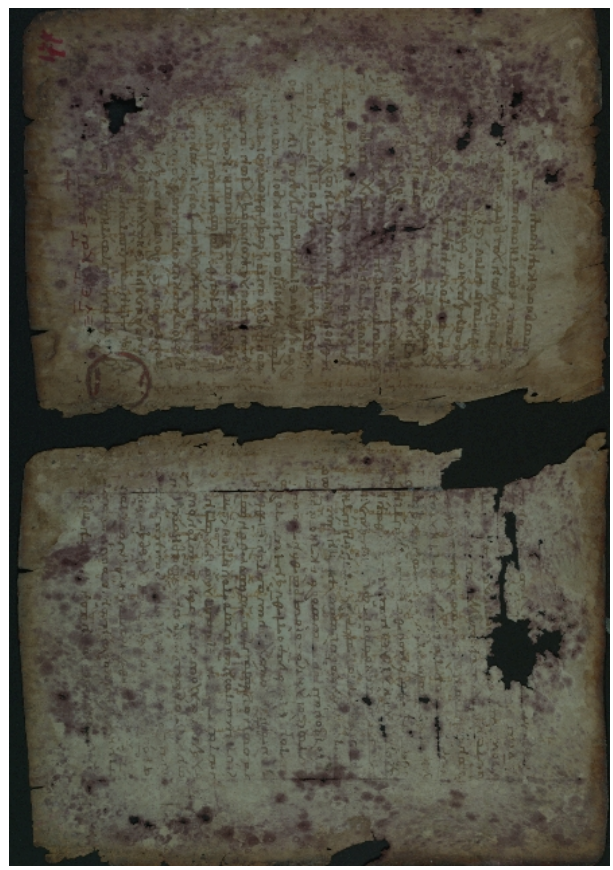

Folio 177 r-v do palimpsesto que contém o Stomákhion. Fonte: <https://www.archimedespalimpsest.net/Data/177v-172r/>. Licença: Creative Commons Attribution 3.0.

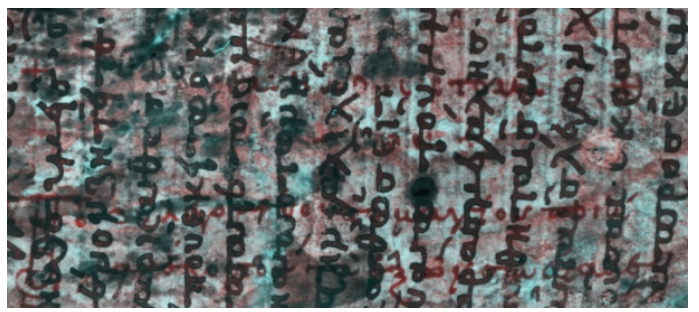

Recorte em que podem ser lidos o título e as primeiras duas linhas do texto. Fonte: <https://www.archimedespalimpsest.net/Data/177v-172r/>.

Licença: Creative Commons Attribution 3.0.

\subsection{Stomákhion: a palavra}

Não é possível dizer com absoluta certeza o que quer dizer otopớxıov (stomákhion). Aparentemente, trata-se de um diminutivo de otó $\mu \alpha \chi o \varsigma$, que significa esôfago, boca do estômago, estômago. Assim, a tradução literal de stomákhion seria algo como estomagozinho. Embora não haja nenhuma conexão evidente entre a palavra e o jogo, os

RBHM, Vol. 21, n 42, pp. 14-51, 2021 
principais estudiosos da obra supõem que ela alude a algo como um frio na barriga, ou seja, a alguma situação de dificuldade. ${ }^{7}$

\subsection{Uma hipótese sobre o conteúdo matemático do tratado: vendo matemática onde poucos veriam}

A descoberta do Stomákhion, inicialmente, não despertou grande interesse. Trata-se de uma das obras arquimedianas mais negligenciadas nos estudos contemporâneos (NETZ, ACERBI \& WILSON, 2004). A pouca atenção que recebeu deve-se, em parte, ao caráter bastante fragmentário do que nos chegou. Outra razão relevante, porém, diz respeito ainda às circunstâncias de sua descoberta. O palimpsesto, quando encontrado, trazia vários textos de Arquimedes. Entre eles, na sua quase integralidade, uma obra capital do grande matemático de Siracusa, cujo desaparecimento era, havia muito tempo, extremamente lamentado: $O$ método ${ }^{8}$. Não à toa, boa parte do interesse e dos esforços acadêmicos concentraram-se sobre essa obra fundamental.

Além disso, por um bom tempo, a sensação geral dos estudiosos perante o Stomákhion era um misto de menoscabo e perplexidade. Afinal, o que pode haver de matematicamente interessante numa obra cujo tema é um jogo recreativo? Abrem-se aqui, para o pesquisador, dois caminhos. O primeiro é contentar-se com aqueles conteúdos que podem ser reconstruídos com relativa segurança a partir dos fragmentos sobreviventes, principalmente a partir daqueles preservados na tradução árabe. Nesse caso, seriam essencialmente dois os resultados expostos por Arquimedes em seu texto: a descrição geométrica da construção das peças do jogo stomákhion a partir de um quadrado; e o cálculo da área dessas peças em relação à área total desse quadrado. É essa a hipótese que segue, por exemplo, Morelli, com argumentos tão prudentes quanto bem documentados ${ }^{9}$.

O segundo caminho consiste em supor algum conteúdo mais substancial para a obra de Arquimedes, ainda que tal conteúdo não possa mais ser reconstituído em seus detalhes. A favor dessa segunda possibilidade contribuem dois argumentos. Um deles diz respeito à relativa pobreza matemática da obra, caso sua intenção original fosse mesmo apenas obter os dois resultados indicados no parágrafo anterior. De fato, ambos são bastante simples, ao menos em comparação com as realizações geralmente notáveis - tanto em dificuldade como em novidade - de seu autor. O outro argumento baseia-se diretamente no

\footnotetext{
7 "Dado que o jogo foi chamado de stomákhion, não há dúvida de que o nome aludia à irritação e ao progressivo desconforto gástrico que invadia os jogadores quando não conseguiam realizar uma determinada figura, como havia visto Heiberg à sua época. O diminutivo não devia estar ligado à leveza do tormentum causado pela dificuldade do jogo e tampouco às reduzidas dimensões físicas do loculus, mas, pelo simples fato de que se tratava de um jogo, devia ter um valor sobretudo afetivo.” MORELLI, 2009, p. 193. Como repara Morelli em nota a esse trecho, tal é também opinião de Heiberg e Netz (ver. HEIBERG, 1907, pp. 240 ss. e NETZ \& NOEL, 2009, p. 244.).

${ }^{8}$ Tradicionalmente chamado somente de $O$ método, esse tratado é escrito em forma de carta dirigida a Eratóstenes, chefe da Biblioteca de Alexandria, e tem, em verdade, um título bem mais longo: Abordagem de Arquimedes

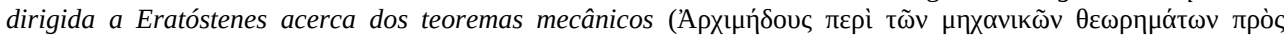

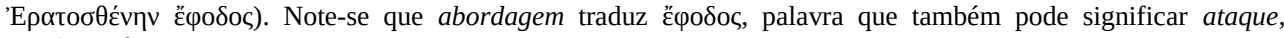
assalto. (cf. KNOBLOCH, 2000, pp. 83-84).

${ }^{9}$ Ver nota 11.
} 
texto do tratado, mais precisamente em um de seus parágrafos iniciais, agora recuperado no palimpsesto grego. Esse parágrafo, que discutiremos em detalhes mais abaixo, parece trazer indicações preciosas a respeito daquela que pode ter sido a questão central de Arquimedes no Stomákhion, bem como do método que pretendia utilizar para enfrentá-la.

Esse segundo caminho foi proposto por Reviel Netz e serve de inspiração ao presente artigo. Netz partiu de um princípio simples de leitura: um escrito de Arquimedes certamente deve ter um conteúdo matemático bastante preciso e não trivial. ${ }^{10}$ Cabe ao pesquisador moderno tentar encontrá-lo. Mas então qual poderia ser esse conteúdo, se o stomákhion - fato bastante conhecido na Antiguidade - era um simples jogo de montar figuras, no qual a criatividade e a capacidade de visualização desempenhavam o papel central?

Como dissemos, as frases iniciais do tratado - que, como é típico da produção arquimediana, deviam pertencer a uma breve introdução - dão algumas pistas a respeito da empreitada matemática à qual seu autor estava se lançando.

“Uma vez que o chamado stomákhion contém uma teoria da múltipla transposição das figuras de que se compõe, considerei necessário, primeiramente, observando-as em relação à grandeza da figura como um todo, estabelecer aquelas em que ele se divide e como ele é medido por cada uma delas; e, em seguida, estabelecer também quais e como são os ângulos quando tomados conjuntamente. Isso está dito para que se tornem conhecidas as composições surgidas dessas figuras: se os lados nelas surgidos estão sobre uma reta ou se falham por pouco, ainda que isso passe despercebido à observação. Pois tais coisas contêm engenho e arte. E mesmo que as figuras assim compostas tenham uma falha mínima, e isso passe despercebido à observação, não é por causa disso que devem ser descartadas.”

Arquimedes parece indicar aqui, não apenas o problema matemático no qual está interessado, mas também o método que pretende utilizar para resolvê-lo. Ele afirma que o jogo contém uma teoria das "múltiplas transposições das figuras". Como interpretar essa expressão? Acontece que a configuração mais básica do stomákhion, aquela a partir da qual as peças são obtidas (e que também devia servir para guardar o jogo) é um quadrado. Além disso, ao brincar com o passatempo, é fácil perceber que há diferentes maneiras de formar esse quadrado. Diante disso, um matemático da estatura de Arquimedes deve ter se perguntado: "De quantas maneiras diferentes é possível montar um quadrado com as peças do stomákhion? Será possível responder a essa pergunta de modo matematicamente rigoroso?” Eis um problema bastante profundo e difícil de resolver.

Supondo que as perguntas formuladas por Arquimedes fossem mesmo essas, o que ele estava procurando pode ser descrito como um princípio de contagem para certa estrutura combinatorial de natureza geométrica. Evidentemente, por se tratar de uma

\footnotetext{
${ }^{10}$ Segundo Netz eta alli há boas razões para supor que o Stomákhion fosse um tratado de maior fôlego, substancialmente maior do que o pequeno trecho que foi possível recuperar. (NETZ, ACERBI \& WILSON, 2004, p. 69).
} 
contagem (“de quantas maneiras...”), o problema aqui colocado demanda vocabulário matemático. A resposta deve ser um número. Mais precisamente, um número inteiro. Isso, porém, não basta para que tal problema assuma caráter matemático. A pergunta "Quantas patas tem uma aranha?” também exige um número inteiro como resposta, mas não envolve um problema propriamente matemático, e sim biológico. O que torna a suposta pergunta de Arquimedes especificamente matemática é a busca de um princípio interno de contagem, isto é, de um modo de determinar a contagem que já esteja dado na própria descrição do problema, mais precisamente, na própria maneira como as peças do stomákhion são obtidas, segundo regras bem determinadas, a partir da divisão de um quadrado. Eis porque um dos temas abordados no tratado deveria ser a descrição precisa das regras para a construção geométrica das peças do jogo. Ora, é justamente isso o que oferece o trecho preservado no fragmento árabe.

Uma vez descrito o modo como o quadrado é dividido - o que corresponde, obviamente, à descrição da forma geométrica das peças -, surge então uma estrutura matemática. Diferentes perguntas podem ser feitas a seu respeito. Por exemplo: “Qual a área de cada uma das peças em relação à área total do quadrado?” Eis aí outro problema abordado no fragmento árabe. Ou então: "Será possível formar com essas peças um triângulo equilátero?” Vale a pena notar que essa última pergunta é matemática na exata medida em que o conceito de "triângulo equilátero" é, também ele, descrito por regras matemáticas precisas. Mas isso é muito diferente de um desafio como o seguinte: "Forme com essas peças um cisne.” Semelhante tarefa, que era a tipicamente proposta aos praticantes do stomákhion, não pertence à matemática. De fato, o que é a forma de um cisne? Um cisne voando, um cisne nadando? Tudo depende da imaginação e dos limites daquilo que se considere aceitável.

No entanto, a pergunta proposta por Arquimedes - como não poderia deixar de ser no caso de um matemático cuja obra é marcada pelo virtuosismo - é mais difícil que as perguntas matemáticas formuladas logo acima. Para Arquimedes, não importa simplesmente saber se determinada figura matemática pode ser contruída a partir de um conjunto de outras figuras matemáticas. Nesse caso, ou bem se afirma que é possível obter tal figura, exibindo como ela pode ser construída; ou bem se afirma que não é possível obtê-la, demonstrando essa impossibilidade. Por exemplo: não é possível construir, a partir de triângulos equiláteros, um triângulo que tenha um ângulo interno de 15 graus. Por quê? Porque o vértice de qualquer triângulo construído a partir de triângulos equiláteros terá de ser, ou o próprio vértice de um desses triângulos, ou um encontro desses vértices, o que corresponde a um ângulo interno de 60 graus ou a um múltiplo de 60 graus.

A questão vislumbrada por Arquimedes parece ser de outro tipo. Já se sabe que, por sua própria construção, as peças do stomákhion podem formar um quadrado. Mas a pergunta fundamental que deve ter ocorrido ao matemático grego é: "De quantas maneiras distintas é possível fazer isso?” Tendo descrito uma estrutura matemática (o conjunto das peças do jogo), Arquimedes possivelmente viu tal estrutura como combinatorial $^{11}$.

\footnotetext{
${ }^{11}$ Acerbi defende que, desde pelo menos o século II a.C., os matemáticos gregos já haviam desenvolvido princípios necessários para calcular a quantidade de combinações distintas de elementos de um conjunto. Sua evidência mais forte é o testemunho de Plutarco sobre a solução apresentada por Hiparco de Niceia para o problema da quantidade de conjunções (combinações usando o conectivo lógico “e”) formadas a partir de dez
} 
Mas o que isso quer dizer? De fato, as peças do stomákhion podem ser combinadas de muitíssimas maneiras diferentes. Em outras palavras, é possível construir muitas configurações com suas peças. Alguém talvez fosse levado a perguntar: "Quantas configurações?” Essa pergunta, porém, ainda não é de interesse propriamente matemático, pois, de modo análogo ao que acontece na busca pela forma de um cisne, carece de determinação mais precisa. Dizer simplesmente "combinações de peças" é algo ainda muito vago, pois não considera o que conta como combinação e o que diferencia uma combinação da outra. Se a pergunta proposta tem algum sentido, sua resposta mais correta é: "Infinitas."

No entanto, sabe-se que ao menos uma dessas configurações é uma forma matemática bem determinada: um quadrado. Pode-se então perguntar: "Quantas configurações diferentes dessas peças formam esse mesmo quadrado?” Eis uma pergunta propriamente matemática, que coloca um problema cuja solução é da mais alta dificuldade.

Assim, assumida a hipótese aqui proposta sobre o modo como Arquimedes aborda o stomákhion, observa-se algo muito significativo, tanto para a matemática em geral como para a matemática de Arquimedes em particular. Inicialmente, o que motiva a pergunta “Quantas configurações diferentes dessas mesmas peças formam esse mesmo quadrado?” é justamente sua dificuldade. Sim, sua pura e simples dificuldade formulada em termos rigorosamente matemáticos. O problema aí implicado, com efeito, está muito longe de apresentar qualquer utilidade imediata e parece nascer de certa curiosidade recreativa, de certo virtuosismo de cálculo.

É importante notar, nesse ponto, que os problemas da área da matemática hoje conhecida como combinatória - os quais podemos definir como problemas de contagem relativos a estruturas matemáticas finitas - demoraram a receber um tratamento sistemático. Apesar de aparições muito esparsas desde a Antiguidade Ocidental e Oriental, tentativas mais consistentes de organizar seus princípios só foram estabelecidas na matemática moderna (Pascal, Newton, Leibniz, Bernoulli, Euler) e só atingiram algum grau de maturidade na passagem do século XIX para o XX, nas obras de uma variedade de autores.

Se for correta a hipótese interpretativa acerca do conteúdo do Stomákhion proposta por Netz e aqui exposta, o tratado é uma das obras pioneiras no âmbito da combinatória talvez a mais brilhante de que temos notícia. Pois o grande matemático grego teria então descoberto uma questão combinatória lá onde poucos conseguiam vê-la - e quase ninguém conseguiria resolvê-la. ${ }^{12}$

sentenças afirmativas. O cálculo de Hiparco estabelece 103.049 conjunções possíveis, exatamente o número apresentado pelo matemático alemão Ernst Schröder, em 1870, como resposta a um problema equivalente, ainda que sob formulação diferente." ver ACERBI (2003). Sobre a hipótese de uma combinatória geométrica no Stomákhion, ver também, NETZ, ACERBI \& WILSON, 2004; NETZ \& NOEL (2009[2007]), pp. 254-257, NETZ (2009), especialmente pp. 19-20, 34, 145-6.

${ }^{12}$ Contra Netz e a hipótese de que no Stomákhion de Arquimedes teria sido formulada uma espécie de cálculo combinatório, Morelli diz que, "nas poucas páginas que restaram [da obra] não há indícios ou mesmo simples sugestões a partir das quais se possa de fato inferir que Arquimedes houvesse intuido e pretendido demonstrar como seria possível obter um quadrado combinando quatorze peças ... em arranjos diferentes.” (MORELLI, 2004, p. 203). Para o filólogo italiano, "das páginas remanescentes do Stomákhion arquimediano, e em particular do fragmento árabe, extrai-se apenas que Arquimedes havia prometido a si mesmo e havia conseguido provar como um quadrado, à semelhança do stomákhion, poderia ser dividido em catorze peças, de modo que cada uma delas fosse comensurável tanto com cada uma das outras como com o quadrado inteiro" (idem, p. 205). Além de apontar uma suposta insuficiência de evidências históricas na hipótese de Netz, Morelli também mobiliza, bem ao fim de 
Ao contrário do que acontece, por exemplo, com permutações e arranjos de elementos discretos (o tema mais comum das análises combinatórias, tanto em suas aparições mais antigas como atualmente), a questão combinatória formulada por Arquimedes tinha como ponto de partida um sistema geométrico. Um tipo de sistema para o qual, até hoje, as questões combinatórias carecem de uma abordagem geral. Isso ocorre por um motivo simples. Se a combinatória trata da contagem de propriedades de sistemas finitos, é preciso primeiramente ver o sistema de combinações geométricas como finito. Mas não há nenhum procedimento padrão para determinar esse limite. Como já dito, a pergunta "De quantas maneiras (distintas) é possível combinar as peças do stomákhion?" não admite resposta unívoca, pois não está determinada o suficiente. Sua resposta mais razoável seria: “Infinitas”. Tal indagação, porém, não leva a qualquer abordagem combinatória. O problema percebido por Arquimedes no stomákhion exige outra pergunta como ponto de partida: "Como reconduzir as infinitas combinações possíveis das peças do jogo ao campo do finito?” Ao determinar com precisão que as configurações das peças do stomákhion deveriam formar um quadrado, Arquimedes encontrou um sistema combinatório sujeito a contagem finita.

seu artigo, um argumento propriamente matemático: nos diferentes arranjos de peças do jogo, os triângulos AMB e MBL contam como uma única peça, o que também ocorre com outros dois pares de peças contíguas. Donde conclui que "para propor e realizar sua pesquisa, Arquimedes não tinha nenhuma necessidade de se referir ao jogo do stomákhion. Ele teria de fato alcançado o mesmo resultado e obtido o mesmo número de combinações possíveis, se tivesse começado de um quadrado dividido, não em quatorze, mas em treze ou doze ou mesmo apenas onze peças”, sendo, portanto, “incompreensível por que Arquimedes teria se dado ao trabalho de registrálos [os lados comuns dos triângulos] com tanto cuidado, dada sua substancial inutilidade.” (idem, p. 205). Netz evidentemente já antecipara essa dificuldade e lhe dera uma resposta: sem dúvida, Arquimedes não tinha nenhuma necessidade do stomákhion para propor o cálculo dos arranjos do quadrado, que, para esse exclusivo fim, seria mesmo inútil, mas ele o quis pelo lúdico de um efeito artístico. É precisamente esse caráter, por assim dizer, “ocioso" ou "inútil” do saber matemático que interessaria a Arquimedes no Stomákhion. Morelli ironiza como “singular” tal explicação e não a aceita. Mas o que permanece completamente ignorado pelo filólogo italiano é que toda a abordagem de Netz sobre o Stomákhion se insere num projeto de pesquisa muito mais amplo e ambicioso sobre a evolução de toda a matemática grega antiga. Nesse projeto, que abrange várias obras dos principais matemáticos gregos, a tese central acerca do período alexandrino sustenta justamente que ele foi determinado por uma concepção lúdica da matemática. Desdobrada ao longo de muitos livros e artigos, a tese de Netz ganha sua expressão mais acabada no livro Ludic Proof - Greek Mathematics and the Alexandrian Aesthetic, em que se lê: “A matemática grega - sempre baseada no mecanismo do diagrama com letras e numa linguagem formular alcançou suas realizações mais notáveis no período helenístico, no qual caracterizava-se por certo estilo 'lúdico', comparável àquele da literatura da mesma época.” (NETZ, 2009, p. X). No mesmo livro, diz o autor no Capítulo 1, “O carnaval do cálculo”, o mais importante para sua interpretação do Stomákhion: "Cremos que houve ao menos dois tratados antigos em combinatória [Arquimedes e Hiparco], ambos levam, por meio de cálculos complexos, a um número grande e complicado (unwieldy). Talvez eles não sejam exatamente o que se costuma associar à matemática grega. Porém, uma vez que se comece a procurá-los, eles se mostram por toda parte: os tratados levam, por meio de um cálculo complexo, de densa estrutura, a números complicados. É a isso que me refiro com o carnaval do cálculo. Nesse capítulo 1, eu mostro sua existência e tento encontrar seus principais temas, que identifico da seguinte maneira: (1) tentativa de capturar o ilimitado (unbounded), (2) textura cognitiva opaca do cálculo, (3) cálculo não utilitário e (4) fascínio com o tamanho.” (pp. 19-20) Em vista dessa grande tese de época, que se fundamenta ao longo de muitos estudos e mobiliza um imenso corpus de textos antigos, poder-se-ia então dizer a Morelli, em defesa de Netz: “Se é certo que tão só com base nos poucos fragmentos dos Stomákhion não se pode extrair uma teoria combinatória, é igualmente certo que, com o foco apenas neles, não se pode invalidar essa hipótese. Ambas as coisas, a tese histórica e a sua crítica, exigem muitíssimo mais filologia e história da ciência.” 
Mas qual método poderia ser trilhado a partir desse grande passo? O terreno não estava mapeado - como não o está ainda hoje. Fez-se necessária uma ideia original para empreender a investigação.

\subsection{Uma hipótese sobre a resolução do problema: tirando o coelho da cartola}

Como visto, a questão matemática descoberta por Arquimedes no Stomákhion lhe impunha uma tarefa tão inovadora quanto difícil: descobrir uma combinatória geométrica, área para a qual não se vislumbra até hoje um método geral.

Nesse sentido, vale destacar que as soluções atualmente disponíveis para o problema de formar quadrados a partir das peças do stomákhion (por exemplo, por meio de complexos raciocínios envolvendo Teoria de Grafos $^{13}$ ou programação de computadores ${ }^{14}$ ) indicam um número surpreendentemente alto de combinações distintas: $17.152^{15}$. Se a intenção de Arquimedes era exercer certo virtuosismo matemático, aqui ele teria encontrado, de fato, um prato cheio.

Mas como Arquimedes, há 2.300 anos, propôs-se a abordar a questão sem dispor de qualquer orientação prévia, sem ter uma bússola que o guiasse pelo novo território que descobrira? Para onde o levou sua intuição aguçada? Que coelho ele tirou da cartola? Parece que Arquimedes, logo ao início do tratado, apresenta uma abordagem original para o problema formulara:

“[...] e, em seguida, estabelecer também quais e como são os ângulos quando tomados conjuntamente. Isso está dito para que se tornem conhecidas as composições surgidas dessas figuras: se os lados nelas surgidos estão sobre uma reta ou se falham por pouco, ainda que isso passe despercebido à observação."

Todo o raciocínio matemático sugerido pelo texto de Arquimedes seria então o seguinte. O stomákhion compõe-se de diferentes peças, razoavelmente irregulares. De fato, não há ali nenhum triângulo equilátero ou mesmo isósceles; e os dois quadriláteros, bem como o único polígono de cinco lados, são positivamente estranhos. Os ângulos internos que surgem nessas figuras são, portanto, bastante variados. Considerando que apenas uma das peças possui um dos lados com comprimento igual ao comprimento do quadrado, os

\footnotetext{
${ }^{13}$ Essa é a abordagem adotada por Fan Chung Graham, professora de Matemática da Universidade de San Diego. Em sua página pessoal, ela comenta que o tema lhe foi sugerido pelo casal de matemáticos Persi Diaconis e Susan Holmes. Solução disponível em: <http://www.math.ucsd.edu/ fan/stomach/main.html>.

${ }^{14}$ William (Bill) H. Cutler foi o vencedor do desafio proposto pelo entusiasta de jogos Joe Marasco em outubro de 2003, apresentando um programa de computador que fornecia 536 soluções diferentes, que é a quantidade total de combinações possíveis, desde que sejam desconsideradas configurações obtidas por rotação, por simetria lateral e por alternância de peças congruentes (ver nota abaixo). Solução disponível em: <http://pi.math.cornell.edu/ mec/GeometricDissections/1.2\%20Archimedes\%20Stomachion.html>.

${ }^{15}$ Esse número pode cair para $536=17.152$ / 32, a depender da possibilidade de "virar o lado da peça” e do modo de interpretar a palavra "distintas”, ou seja, caso sejam descontadas como iguais soluções obtidas por rotação do quadrado, por simetria lateral e por alternância de peças congruentes. Mas mesmo desse modo mais "austero” de contagem das soluções, o número continua sendo impressionante.
} 
outros três lados do quadrado têm de ser formados pela combinação de mais de uma peça. Para que isso seja possível - lembre-se que os lados do quadrado são linhas retas -, é preciso que certos ângulos, quando "tomados conjuntamente", formem linhas retas (um ângulo de 180 graus, em linguagem atual). Segue-se daí a necessidade de calcular o valor de todos os ângulos internos de todas as peças. De posse desses valores, é possível encontrar - aí sim, por uma combinatória discreta, bem mais simples de se fazer - todos os possíveis encontros de 180 graus. A partir dessa lista dos valores dos ângulos é que seria possível determinar o número exato de combinações capazes de formar o quadrado.

Mas terá Arquimedes efetivamente obtido o número que procurava? E teria sido esse o raciocínio que elaborou para calculá-lo? O pouco que sobrou do texto do Stomákhion, infelizmente, não permite resposta. No entanto, dada a qualidade extraordinária das demais obras desse matemático grego e sua segurança e engenhosidade ao início do tratado, é muito plausível que ele tenha encontrado uma boa solução para seu problema.

\subsection{Matemática como cálculo, não como observação}

Cabe uma última consideração sobre a maneira como Arquimedes compreende o trabalho matemático, expressa de maneira bastante clara ao início do Stomákhion. Arquimedes enfatiza que o estudo dos ângulos, a partir do qual deseja obter a resposta procurada para seu problema, deve ser feito por meios estritamente matemáticos. Nessa empreitada, os sentidos não podem ser o juiz final, nem podem desempenhar papel determinante. Apenas os cálculos são capazes de mostrar quais ângulos combinam-se para formar uma reta, e quais "falham por pouco, ainda que isso passe despercebido à observação". Esse é um ponto importante para Arquimedes, que não se furta a insistir no assunto.

"Pois tais coisas [cálculos matemáticos] contêm engenho e arte. E mesmo que as figuras assim compostas tenham uma falha mínima, e isso passe despercebido à observação, não é por causa disso que devem ser descartadas.”

Em outras palavras, há somente uma razão para descartar determinada combinação: que os cálculos mostrem que ela é inadequada, na medida em que os ângulos não somam o que deveriam somar. Trata-se da reafirmação de um ponto metodológico tão claro quanto importante. A imagem logo abaixo mostra uma montagem do stomákhion que "falha por pouco" e cujas falhas talvez "passem despercebidas à observação" - mas certamente não às contas de Arquimedes! 


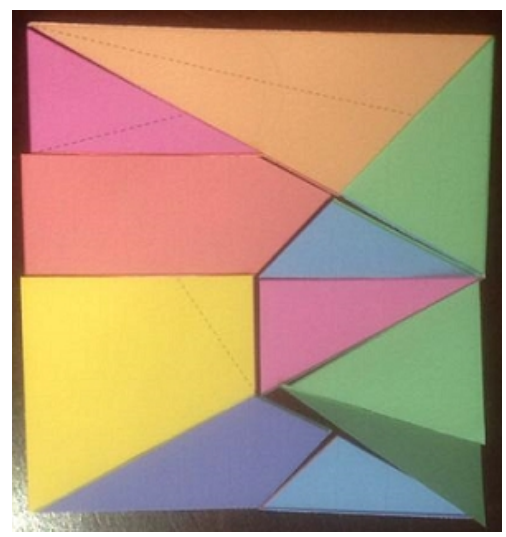

Um quase quadrado, montado empiricamente e capaz de enganar os sentidos.

Quantos casos como esse, de "quase-quadrados”, podem ser montados? Essa já seria outra pergunta. Mas uma pergunta - a não ser que se especifique com precisão qual é a falha permitida - que escapa à matemática.

\section{Sobre a tradução}

\subsection{Critério e equipe}

A tradução e as notas do Stomákhion como um todo (seja da parte em grego, seja da parte em árabe) é fruto de um trabalho em equipe que reuniu professores e estudantes das áreas de grego antigo, latim, língua árabe, matemática e filosofia. Discutida ao longo de muitas jornadas de trabalho em grupo, a presente tradução buscou, sem sacrificar a fluência da leitura e a clareza dos argumentos, manter-se o mais possível rente ao original na letra e no efeito. Por motivo de clareza, foram inseridas no texto vernáculo palavras que não estão expressas no original. Para indicá-lo, tais palavras aparecem sempre entre colchetes.

\subsection{Fontes}

Quanto ao fragmento em grego, que tem uma única fonte, o assim chamado "códex de Arquimedes" (ver NETZ \& NOEL, 2009 [2007]), a tradução se baseou no texto com aparato crítico-filológico estabelecido por NETZ, ACERBI \& WILSON (2004), que aparece no tópico 6.1 respeitando o alinhamento do palimpsesto e permitindo o cotejo. Sobre as convenções adotadas nessa publicação, dizem os autores: "O que se segue é uma transcrição; portanto, as correções estão registradas no aparato. Dentro de parênteses esquinados < > estão restaurações de partes invisíveis do texto; os parênteses curvos ( ) encerram palavras escritas como compendia [abreviações do texto original]. Aspirações, acentos e pontuação foram adicionados. O iota é adscrito, como no manuscrito. A imagem 
[o diagrama] é uma reprodução fiel da que consta no manuscrito.” (Sobre os diagramas ver também tópico 4). Além dos símbolos filológicos convencionais, o texto grego apresenta à esquerda sua localização na edição de Heiberg (por exemplo, H:416 indica ARQUIMEDES, 1910-15, vol. II, p. 416) e à direita sua localização no códex (por exemplo, 177r. col. 2 indica folium 177, recto, columna 2, enquanto 177v. col. 1 indica folium 177, verso, columna 1).

Quanto ao fragmento árabe, que tem 4 fontes, a tradução se baseou no texto estabelecido por Suter (1899), também apresentado abaixo para cotejo. Na sua edição, Suter valeu-se apenas de dois manuscritos preservados em Berlim, que chamou de "códice A" (uma cópia de 1651) e "códice B" (outra cópia cerca de 60 anos mais recente). Segundo Suter, não houve cotejo com os dois outros manuscritos existentes, situados em Londres e Oxford, pelo fato de os códices à sua disposição serem bastante coincidentes e claros. (Para indicações bibliográficas mais precisas, ver SUTER, 1899, p. 494). Note-se ainda que, no texto da tradução alemã de Suter, as sequências de letras pelas quais são designadas as diferentes figuras geométricas aparecem muitas vezes, possivelmente para padronizar sua notação, em ordem diferente daquela que consta no texto árabe. Na presente tradução, seguimos sempre a ordem original do texto árabe, gerando assim algumas discrepâncias com o trabalho de Suter (todas elas, evidentemente, sem qualquer implicação matemática). Além disso, porque o alfabeto árabe é desconhecido do leitor brasileiro, ao designar os elementos das construções geométricas, optamos por usar, ao lado de letras árabes, também letras latinas. Por fim, cabe ressaltar que o fragmento árabe certamente não reproduz a formulação exata do texto de Arquimedes, Como aponta Netz, os matemáticos árabes "com frequência reescreviam suas fontes, reduzindo-as, reformulando-as etc. Claramente esse foi o caso do Stomákhion. O manuscrito encontrado por Suter infelizmente não passa de uma redução árabe de uma pequena parte do texto original de Arquimedes” (NETZ \& NOEL, 2004 [2007], p. 245).

\subsection{Notas e diagramas}

Quanto ao texto grego, as notas matemáticas são de pé e estão indicadas por números indoarábicos, ao passo que as notas filológicas são de fim e estão indicadas por números romanos. Quanto ao texto árabe, todas notas são de pé e estão indicadas por números indoarábicos.

A fim de permitir comparação e facilitar o acompanhamento dos raciocínios, após as traduções, são apresentados o diagrama do códex e 2 diagramas reconstruídos (ver tópico 4).

\section{Agradecimentos}

Os autores do artigo agradecem o apoio dos professores André K. T. Assis (Instituto de Física - Unicamp) e Nigel Wilson (Lincoln College - Oxford). Agradecemos especialmente ao professor Reviel Netz (Stanford), que, numa atitude de generosa colaboração científica, não apenas permitiu a reprodução do texto grego estabelecido em NETZ, ACERBI \& 
WILSON, 2004, como nos enviou seus mais recentes estudos filológicos sobre o texto do Stomákhion, permitindo-nos sua utilização. Por causa de seu caráter ainda muito hipotético, decidimos não aproveitar tal material nesta tradução. Uma vez publicada a nova versão de Netz, é possível que ela traga nova luz à compreensão do texto.

Agradecemos, finalmente, a todos os participantes do Grupo Gnómon, ligado à Areté - Centro de Estudos Helênicos, instituição no seio da qual este trabalho foi desenvolvido: Augusto de Amaral Sibo, Eduardo Kickhöfel, Fernanda Abrahão, Marcos Barreiros, Nataly Ianicelli, Rodrigo Lima de Oliveira e Taimara Passero.

\section{Bibliografia}

ACERBI, Fabio. 2003. On the shoulders of Hipparchus: A reappraisal of ancient Greek combinatorics. Archive for History of Exact Sciences, 57(6), 465-502.

ARQUIMEDES. 2009. Tratados. Vol. II. Introdução, tradução e notas de Paloma Ortiz García. Madri: Gredos.

ARQUIMEDES. 2002 [1971]. Euvres. Tome III : Des corps flotants - Stomachion - La méthode - Le livre des lemmes - Le problèmes des bœufs. Texto estabelecido e traduzido por Charles Mugler. Paris : Belles Lettres.

ARQUIMEDES. 1910-15. Opera omnia, cum commentariis Eutocii, iterum edidit 1. L. Heiberg. 3 vols. Leipzig, B. G. Teubner (reprint ed.: Stuttgart und Leipzig, B. G. Teubner 1972).

ASSIS, André Koch Torres. 2008. Arquimedes, o centro de gravidade e a lei da alavanca. Montreal: Apeiron.

AUSONIUS, Decimus Magnus. 1919. Works of Ausonius, with an english translation by Hugh G. Evelyn White, Loeb Classical Library, vol. I. Londres: Willian Heinemann - New York: G. P. Putnam's Sons.

EUCLIDES. 1969-1977. Elementa, post 1. L. Heiberg edidit E. S. Stamatis. 5 vols. Leipzig, B. G. Teubner.

EUCLIDES. 2009. Os Elementos. Tradução de Irineu Bicudo. São Paulo: UNESP.

HEIBERG, Johan Ludvig. 1907. Eine Neue Archimedeshandschrift. Hermes, 42, 234-303.

KNOBLOCH, Eberhardt. 2000. Archimedes, Kepler, and Guldin: the role of proof and analogy. In: Festschrift zum siebzigsten Geburstag von Matthias Schramm, Mathesis, Berlin, Diepholz. 
KNORR, Wilbur Richard. 1996. The Method of Indivisibles in Ancient Geometry. In: R. CALINGER (org.), Vita Mathematica. Historical research and integration with teaching, The Mathematical Association of America, 67-86.

MINONZIO, Franco. 2000. Lo Stomachion di Archimede. In: Lettera matematica, 35, 4147.

MORELLI, Giuseppe. 2009. Lo Stomachion di Archimede nelle testimonianze antiche. Bollettino di storia delle scienze matematiche, Vol. XXIX, Fasc. 2, 181-206.

MUGLER, Charles. 1958. Dictionnaire historique de la terminologie géométrique des grecs, Klincksieck, Paris

NETZ, Reviel. 2009. Ludic Proof - Greek Mathematics and the Alexandrian Aesthetics, Cambridge University Press, NY.

NETZ, Reviel \& NOEL, William. (2009 [2007]). Códex Arquimedes: como um livro de orações revelou a genialidade de um dos maiores cientistas da antiguidade. Rio de Janeiro: Record.

NETZ, Reviel \& NOEL, William. 2007. The Archimedes Codex: How a Medieval Prayer Book is Revealing the True Genius of Antiquity's Greatest Scientist. Cambridge: Da Capo Press.

NETZ, Reviel, ACERBI, Fabio \& WILSON, Nigel. 2004. Towards a Reconstruction of Archimedes' Stomachion. Sciamvs, n. 5, 67-99.

SUTER, Heinrich. 1899. Der Loculus Archimedius oder das Syntemachion des Archimedes. Zum ersten mal nach zwei arabischen Manuskripte der Koeniglichen Bibliothek in Berlin herausgegeben und ubersetzt; in: Zeitschrift für Mathematik und Physik, 44, SupplementHeft (Cantorfestschrift), zugleich neus Heft der Abhandlungen zur Geschichte der Mathematik, 9, Leipzig, 491-499.

Henrique Marins de Carvalho
Instituto Federal de Educação, Ciência e
Tecnologia de São Paulo (IFSP) - Campus São
Paulo
E-mail: hmarins@ifsp.edu.br


Jamil Ibrahim Iskandar

Professor de filosofia medieval árabe Universidade Federal de São Paulo (Unifesp) -

Campus Guarulhos - Unifesp

E-mail: jamil.iskandar@yahoo.com.br

\section{Tiago Tranjan}

Departamento de Filosofia - Universidade Federal de São Paulo (Unifesp) - Campus Guarulhos

E-mail: ttranjan@hotmail.com

João F. N. B. Cortese

Instituto de Biociências - Universidade de São

Paulo (USP) - Campus de São Paulo

E-mail: joaocortese@gmail.com

\section{Vicente A. de Arruda Sampaio}

Faculdade de São Bento

E-mail: sampaio.vicente@gmail.com 
4. Diagramas (ver NETZ, ACERBI \& WILSON, 2004, pp. 92, 94)

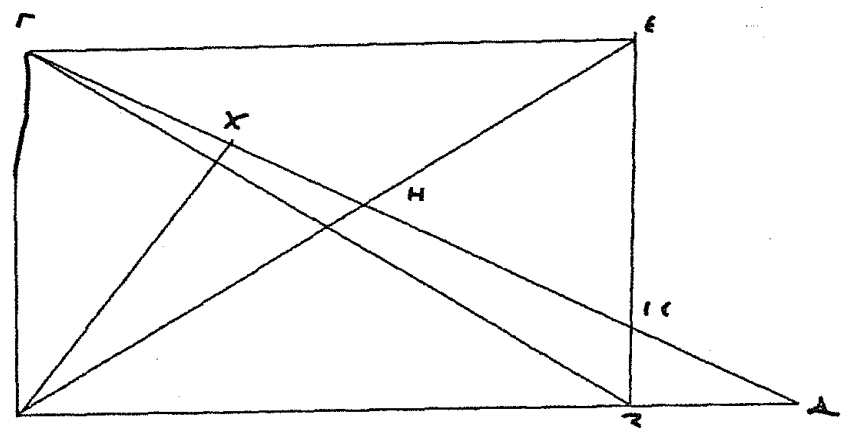

Fac-símile do diagrama do códex.

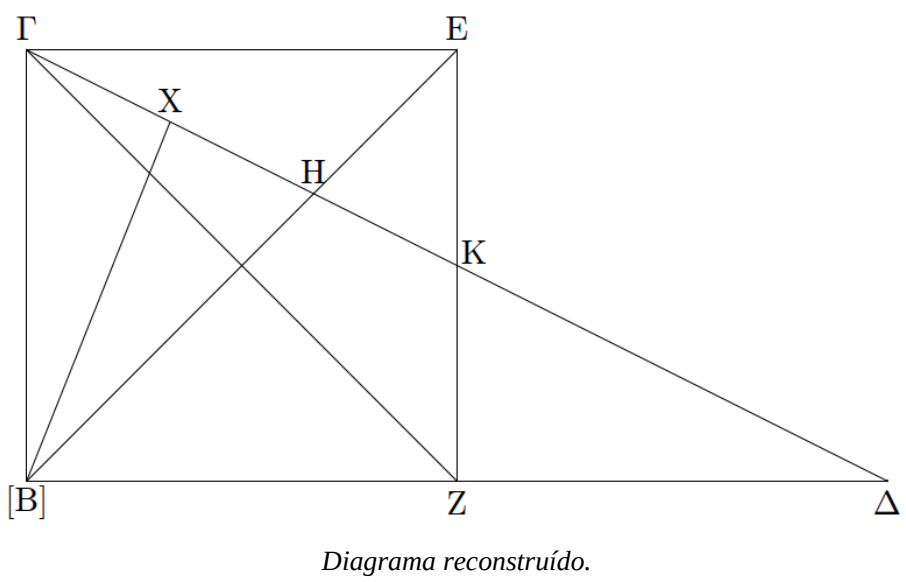

A Análise dos manuscritos indica com toda probablidade que Arquimedes não utilizava diagramas com medidas exatas das figuras construídas. Isso é fácil de perceber pela comparação dos diagramas acima (note-se, por exemplo, como saltam aos olhos as discrepâncias no quadrado $\Gamma Z$ e nos segmentos $Z \Delta$ e $\Gamma \Delta$ ). Essa prática de Arquimedes indica um importante princípio: a matemática é uma ciência demonstrativa em que a atuação dos sentidos não desempenha papel fundamental. 


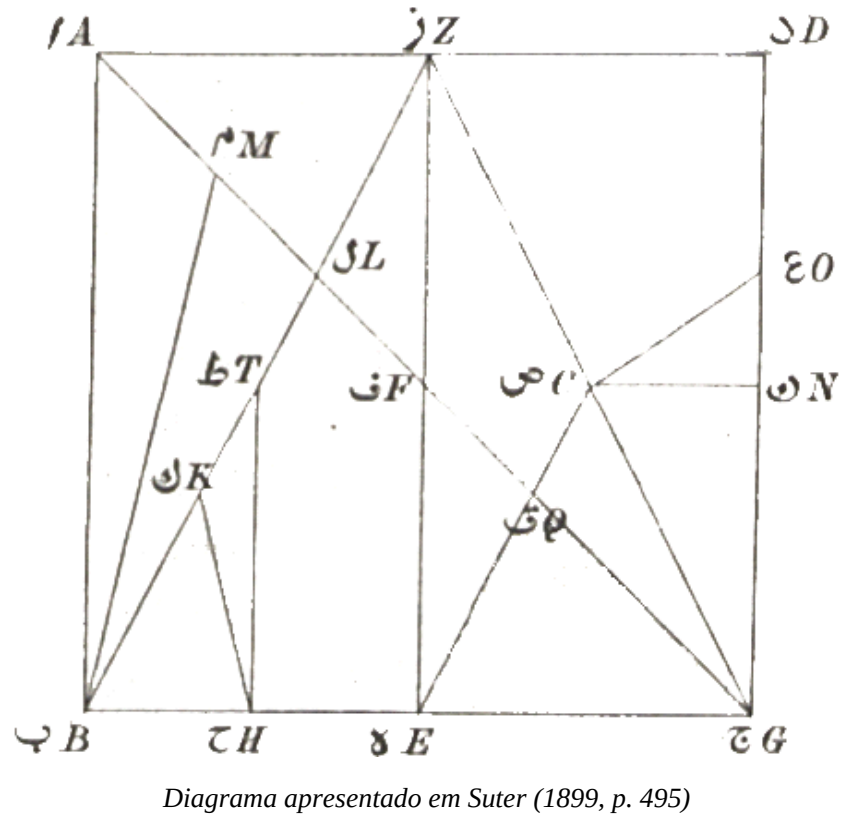

RBHM, Vol. 21, n ${ }^{\circ}$ 42, pp. 14-51, 2021 
Henrique Marins de Carvalho et al.

\section{Tradução}

\subsection{Stomákhion (tradução do texto grego)}

De Arquimedes STOMA

..... ON

Uma vez que o chamado stomákhion contém

uma teoria da múltipla transposição

das figuras de que se compõe ${ }^{\mathrm{i}}$,

considerei necessário, primeiramente, observando-as

em relação à grandeza da figura como um todo,

estabelecer aquelas em que ele se divide

e como ele é medido por cada uma delas;

e, em seguida, estabelecer também quais e como

são os ângulos quando tomados conjuntamente ${ }^{\mathrm{ii}}$.

Isso está dito para que

se tornem conhecidas as composições ${ }^{\mathrm{iii}}$

surgidas dessas figuras:

se os lados nelas surgidos

estão sobre uma reta ou se falham por pouco,

ainda que isso passe despercebido à observação ${ }^{\text {iv }}$.

Pois tais coisas contêm engenho e artev .

E mesmo que as figuras assim compostas tenham

uma falha mínima, e isso passe despercebido à observação, 
não é por causa disso que devem ser descartadas.

Pois bem, há uma quantidade não pequena de figuras

feitas com essas [figuras menores], por ser possível

mover um mesmo lugar para outro ${ }^{\mathrm{vi}}$,

quando uma figura igual [em tamanho] e equiangular

é transposta e assume outra posição.

Além disso, duas figuras combinadas equivalem

a uma única figura quando são iguais [em tamanho]

e semelhantes a essa única figura;

ou ainda, quando duas figuras combinadas

são iguais [em tamanho] e semelhantes

a duas [outras] figuras combinadas -

muitas figuras são compostas a partir de transposições.

Primeiro, comecemos delineando um teorema ${ }^{\text {vii }}$

nessa direção. Seja então um paralelogramo

retângulo $Z \Gamma^{16}$ e seja $E Z$

dividido ao meio em $\mathrm{K}^{17}$. E sejam traçados,

a partir de $\Gamma$ e $\mathrm{E}, \Gamma \mathrm{K}$ e BE.

Deve-se demonstrar que ГВ é maior que $\mathrm{BH}$.

\footnotetext{
${ }^{16}$ Apesar de serem indicados apenas dois vértices, as construções no decorrer do texto deixam claro que se trata do quadrilátero ZEГВ. Para construir o paralelogramo: cf. Eucl. I, proposições 46, 11, 31.

${ }^{17}$ Para dividir uma reta ao meio: cf. Eucl. I, proposição 10.
} 
Henrique Marins de Carvalho et al.

Sejam estendidos $\Gamma \mathrm{K}$ e BZ ${ }^{18}$,

encontrando-se em $\Delta$,

e seja traçado $\Gamma Z$. Uma vez que EK é igual a KZ

e que $\Gamma E$, isto é, $B Z$, é igual a $Z \Delta^{19}$, de modo que

$\Gamma \mathrm{Z}$ é maior que $\mathrm{Z} \Delta^{20}$, por conseguinte, também o ângulo

$\mathrm{Z} \Delta \Gamma$ é maior que $\mathrm{Z} \Gamma \Delta^{21}$.

Mas os ângulos HB $\Delta$ e ВГZ são iguais,

pois cada um é metade de um reto ${ }^{22}$.

Por conseguinte, ГНВ também é maior que НГВ

(pois ГHB é igual aos dois ângulos [somados],

internos e opostos, $\mathrm{HB} \Delta \mathrm{e} H \Delta \mathrm{B}^{23}$ ),

${ }^{18}$ Para estender uma reta: cf. Eucl. I, postulado II.

${ }^{19}$ Cf. por ex. Eucl. I, proposições 6, 13.

${ }^{20}$ Cf. por ex. Eucl. I, proposições 17, 19.

${ }^{21}$ Cf. por ex. Eucl. I, proposição 18.

${ }^{22}$ Cf. por ex. Eucl. I, proposição 4. Lembremos que Arquimedes começa sua demonstração assim - "Seja então um paralelogramo retângulo Z $\Gamma^{\prime}$ "-, sem especificar, portanto, o tipo de paralelogramo a que sua demonstração se aplica. Por outro lado, como o tema de seu tratado é o stomákhion, o paralelogramo em vista é um quadrado. Vale a pena observar que o resultado " $\Gamma \mathrm{B}>\mathrm{BH}$ " não é válido em geral, mas o é, com algumas modificações na demonstração apresentada por Arquimedes, para quaisquer paralelogramos em que a razão entre os lados seja menor que $\frac{\sqrt{5}}{2}$. Tal fato pode ser assim demonstrado: adotemos, para facilitar, a simbologia $\Gamma B=a, B Z=b$. Dos dados do enunciado, temos que os triângulos $\Gamma \mathrm{BH}$ e KEH são semelhantes, com razão de semelhança 2:1; dessa semelhança e do fato que $\mathrm{H}$ divide a diagonal $\mathrm{BE}$ em duas partes na razão 2:1, têm-se BH/BE=2/3. Como BE é a diagonal do retângulo, usando a simbologia sugerida, temos: $\frac{b}{a}<\frac{\sqrt{5}}{2}$. Para que se tenha ГВ maior que BH, a razão entre $a$ e $\frac{2}{3} \sqrt{a^{2}+b^{2}}$ deve ser maior que 1. Desenvolvida esta desigualdade, temos $\frac{b}{a}<\frac{\sqrt{5}}{2}$, ou seja, nos casos em que a razão entre a base e a altura do retângulo for menor que $\frac{\sqrt{5}}{2} \cong 1,12$ (em especial, no caso de um quadrado de razão igual a 1), vale o teorema enunciado por Arquimedes.

${ }^{23}$ Vale notar que (i) $Г \mathrm{HB}=\mathrm{HB} \Delta+\mathrm{H} \Delta \mathrm{B}$, е НГВ $=\mathrm{Z} \Gamma \mathrm{B}+\mathrm{Z} \Gamma \Delta$; (ii) $\mathrm{B} \Gamma \mathrm{Z}=\mathrm{HB} \Delta$ e $\mathrm{Z} \Delta \Gamma>\mathrm{Z} \Gamma \Delta$; (iii) pelo diagrama, $\mathrm{H} \Delta \mathrm{B}=\mathrm{Z} \Delta \Gamma$; logo, segue que $Г Н \mathrm{~B}>\mathrm{H} \Gamma \mathrm{B}$. 
de modo que ГВ é maior que $\mathrm{BH}^{24}$; portanto,

se $\Gamma \mathrm{H}$ for dividido em dois, em $\mathrm{X}$,

o ângulo ГXВ será obtuso.

De fato, uma vez que $\Gamma \mathrm{X}$ é igual a XH e que XB é comum,

dois lados [de um triângulo] são iguais a dois lados [do outro triângulo];

e, sendo a base $\Gamma \mathrm{B}$ maior que $\mathrm{BH}^{25}$,

o ângulo [de um] também é maior que o ângulo [do outro] ${ }^{26}$.

Portanto, o ângulo ГXВ é obtuso, e é agudo

o adjacente. Е ГВН é metade de um reto,

supondo-se o paralelogramo

como [quadrado] ${ }^{27}$,

e BXH é agudo; e tampouco são iguais

os ângulos restantes de ГВH, e este triângulo

está composto e dividido pela parte adicionada ${ }^{28}$.

\footnotetext{
${ }^{24}$ Aqui Arquimedes conclui a demonstração do teorema proposto em 177v. col.1 l.16.

${ }^{25}$ Cf. por ex. Eucl. I, proposição 19.

${ }^{26}$ Cf. Eucl. I, proposição 25.

${ }^{27}$ Adotamos aqui a única tradução que confere sentido matemático ao texto (ver nota 22). Netz supõe para o trecho

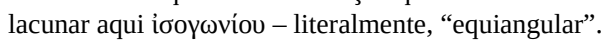

${ }^{28}$ A partir daqui o texto grego torna-se muito incerto, sendo difícil extrair seu conteúdo matemático. Nesta passagem, nossa tradução aponta na direção da seguinte ideia: o triângulo ГBH é dividido pelo segmento BX nos triângulos ГBX e EBX, sendo assim por eles composto.
}

RBHM, Vol. 21, n 42, pp. 14-51, 2021 


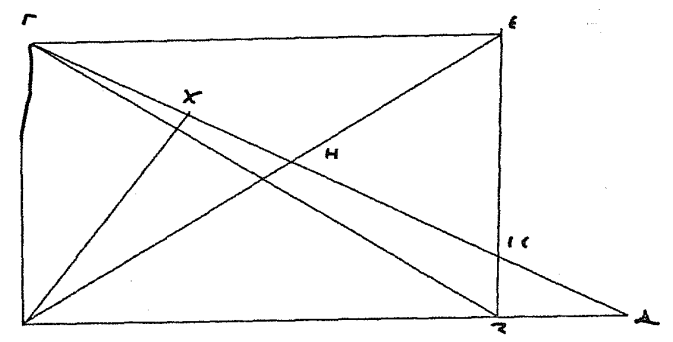

Seja uma pequena área retangular de lados dobrados,

... tendo $\mathrm{AB}$ como diagonal,

tendo a reta $Г$ A como o dobro de $Г В$,

... tendo a espessura ${ }^{29} \ldots$

$\cdots$

... ser possível ajustar como se fossem retas,

uma vez que os segmentos têm uma ordem. E

seja ГА cortada em dois, em E,

e EZ traçada [passando] por E, paralelamente a $\mathrm{B}^{30}$;

então, [os paralelogramos] ГZ e ZA são quadrados.

Sejam traçadas $\Gamma \Delta$, BE e E $\Delta$ como diagonais;

sejam $\Gamma \mathrm{H}$ e E $\Delta$ cortadas em dois, em $\Theta$ e X;

sejam ligadas $\mathrm{B} \Theta$ e XZ;

e sejam traçadas $K \Lambda$ e $X \Xi$,

passando por $\mathrm{X}$ e $\mathrm{K}$, paralelas a $\mathrm{B} \Delta$.

${ }^{29}$ Aparentemente, Arquimedes está construindo um novo retângulo (BA ou $\Gamma \Delta$ ), a partir do quadrado $\Gamma Z$ do stomákhion. (ver nota 22).

${ }^{30}$ A partir de um ponto, traçar uma reta paralela a outra: Eucl. I, proposição 31. 
Portanto, por meio do teorema exposto,

o ângulo em $\Theta$ do triângulo $В Г \Theta$ é obtuso,

enquanto é evidente que o ângulo restante é agudo.

E é evidente que é maior ...

\subsection{Stomákhion (tradução do texto árabe)}

Em nome de Deus, O Misericordioso, O Misericordiador ${ }^{31}$

Livro de Arquimedes sobre a divisão da figura denominada stomákhion em catorze figuras parciais que lhe são adequadas ${ }^{32}$. Traçamos quatro linhas paralelas $\mathrm{ABGD}^{33}$, de modo que $\mathrm{AD}$ seja igual a $\mathrm{AB}$, e dividimos a linha $\mathrm{BG}$ em duas partes iguais no ponto $\mathrm{E}$, e erguemos [perpendicularmente] sobre a linha BG uma linha EZ. Traçamos as linhas [diagonais] AG, BZ e ZG e dividimos, ainda, BE em duas partes no ponto $\mathrm{H}$, e elevamos [perpendicularmente] $\mathrm{HT}$ sobre $\mathrm{BE}$. Colocamos uma régua no ponto $\mathrm{H}$, inclinando-a na direção do ponto A e, em seguida, desenhamos uma linha HK e dividimos AL em duas metades no ponto $\mathrm{M}$ e ligamos $\mathrm{BM}$; dividimos, então, $\mathrm{AE}$ de lados paralelos ${ }^{34}$ em sete partes; e dividimos GD em duas partes iguais no ponto $\mathrm{N}$ e a linha ZG em duas metades no ponto $\mathrm{C}$, traçando $\mathrm{EC}$; colocamos uma régua sobre os pontos $\mathrm{B}, \mathrm{C}$ e desenhamos $\mathrm{CO}$ e $\mathrm{CN}$, e assim, então, dividimos ZG de lados paralelos em outras sete partes. Mas a figura de lados paralelos sob AG, como um todo, é dividida em catorze partes.

Nós demonstraremos que cada uma dessas catorze partes tem relação ${ }^{35}$ com [a figura] de lados paralelos como um todo. Pois, sendo ZG a diagonal do retângulo ZG, o triângulo DZG é a metade desse retângulo e, por isso, é um quarto do quadrado ${ }^{36}$; porém, o triângulo GNC é igual a um quarto do triângulo DZG porque, fazendo chegar o prolongamento EC

${ }^{31} \mathrm{O}$ muçulmano tem o costume de iniciar qualquer atividade com esta frase.

${ }^{32} \mathrm{O}$ propósito deste fragmento consiste em calcular a área de cada peça do stomákhion em relação à figura como um todo. O verbo utilizado no texto árabe é munássibah (مناسبه), que indica a noção de adequação, conveniência ou ajuste (das peças em relação à figura). Do ponto de vista matemático, o resultado que será obtido pode ser formulado, em linguagem moderna, da seguinte maneira:

1. a área de todas as peças é uma fração racional da área total do stomákhion;

2. além disso, a área de todas as peças, com exceção de uma, pode ser expressa como fração unitária da área total do stomákhion, e mesmo aquela única exceção pode ter sua área expressa como soma de duas frações unitárias da área total.

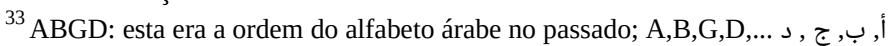

${ }^{34}$ Isto é, o retângulo cujos vértices opostos são A e E. No restante da tradução, designamos os quadriláteros ora por duas letras (como aqui), ora por quatro letras - sempre de acordo com o que acontece no texto árabe. 35 Ver nota 32

${ }^{36}$ O quadrado é designado em árabe, por perífrase, como a figura de "lados paralelos por excelência”. Em árabe: al-mutawázi al-adlá' al-a'zam (المتوازي الاضلاع الاغظم). Isso acontece apenas duas vezes no fragmento, e em ambas optamos pela tradução mais direta “quadrado”.

RBHM, Vol. 21, n 42, pp. 14-51, 2021 
ao ponto D, o triângulo GDC será a metade do triângulo GDZ e igual à soma dos dois triângulos GNC e DNC; então, o triângulo GNC é a décima sexta parte do quadrado. Se imaginarmos $^{37}$ a linha $\mathrm{CO}$ traçada em direção ao ponto $\mathrm{B}$, como de fato o foi, NC será paralela ao lado BG, [do quadrado] ou do triângulo BGO; então, tem-se que a relação de BG com NC é igual à relação de $\mathrm{GO}$ com $\mathrm{NO}^{38}$. Mas a linha BG é o quádruplo da linha NC, e, consequentemente, a linha GO é o quádruplo da linha NO; e a linha GN é o triplo da linha NO e o triângulo GNC é o triplo ${ }^{39}$ do triângulo CNO. Porém, ficou evidenciado que o triângulo GNC é a décima sexta parte de ABGD de lados paralelos; com efeito, o triângulo NCO é a quadragésima oitava parte de ABGD de lados paralelos, e o triângulo GDZ é um quarto da área da [figura] de lados paralelos; por isso, GNC é a décima sexta parte dele, e o triângulo NCO é a quadragésima oitava parte dele. Resta, então, que ZCOD de quatro lados tem uma área igual a um sexto da área de ABGD. Imaginemos, também, a linha NC traçada em direção ao ponto $\mathrm{F}$, e seja CF paralela a GE; temos, portanto, que EG está para CF assim como EQ está para CQ, e assim como GQ está para $\mathrm{FQ}^{40}$. Estimamos então que EQ é o dobro de QC, e GQ o dobro de QF; então, o triângulo EQG é o dobro de cada um dos dois triângulos QGC e QEF ${ }^{41}$. Porém, ficou evidente ${ }^{42}$ que o triângulo EZG é o dobro do triângulo EFG, pois a linha ZE é o dobro da linha EF e o triângulo ZEG é igual a um quarto de ABGD de lados paralelos; então o triângulo EFG é igual a um oitavo de ABGD; porém, como o triângulo EFG é o triplo de cada um dos dois triângulos FEQ e GQC, então cada um desses dois triângulos é igual à vigésima quarta parte de ABGD de lados paralelos. E o triângulo EGQ é o dobro de cada um dos triângulos FEQ e QGC, portanto uma décima segunda parte de ABGD de lados paralelos. Ademais, sendo a linha ZF igual a EF, então o triângulo ZFG é igual ao triângulo $\mathrm{FEG}^{43}$; se retirarmos o triângulo QGC e o triângulo igual EQF, resta então que FZCQ de quatro lados ${ }^{44}$ é igual a QEG e, assim, FZCQ também é uma décima segunda parte de AG e, deste modo, ZG foi dividido em sete partes. Passemos à

\footnotetext{
37 "Imaginarmos": traduz a palavra árabe tawahmná, derivada de Wahm, que se refere à faculdade estimativa. Outra tradução seria "admitirmos", "supusermos".

${ }^{38}$ Cf. Euclides, Elementos, VI, 2.

${ }^{39} \mathrm{Cf}$. Euclides, Elementos, VI, 1.

${ }^{40} \mathrm{Cf}$. Euclides, Elementos, VI, 4.

${ }^{41}$ Cf. Euclides, Elementos, VI, 1. Ao afirmar que as linhas CF e GE são paralelas, ficam identificados os pares de ângulos congruentes QCF e QEG, e QFC e QGE, o que implica a semelhança dos triângulos QEG e QCF, com razão de semelhança 1:2, verificada pelo fato de que EG é o dobro de QC, por construção. Assim, temos que as áreas dos referidos triângulos estão na razão de 1:4, ou, simbolicamente, QEG = 4 QCF. Analisando os triângulos CFG e EGC, que têm a mesma altura e bases na razão 1:2, concluímos que EGC = 2 CFG. Mas EGC é composto dos triângulos QEG e QGC, enquanto CFG é composto de QCF e QGC; logo, QEG + QGC = 2.(QCF+QGC). Considerando a relação já apresentada anteriormente $(\mathrm{QEG}=4 \mathrm{QCF})$, temos que $\mathrm{QEG}+\mathrm{QGC}=1 / 2 . \mathrm{QEG}+2$.QGC. Após alguns procedimentos, temos que QGC=1/2.QEG, a primeira das conclusões desejadas. Avaliando os pares de triângulos QEG e QEF, e QEG e QGC: o primeiro par compõe o triângulo EGF enquanto o segundo compõe EGC, de mesma base (EG) e mesma altura. Assim, QEF é igual a QGC e têm - cada um deles - a metade da área de QEG.

${ }^{42}$ Cf. Euclides, Elementos, VI, 1

${ }^{43}$ Cf. Euclides, Elementos, VI, 1

${ }^{44}$ No árabe, aparece “de quatro lados paralelos”. Trata-se, porém, de um equívoco matemático.
} 
divisão do outro quadrilátero: sendo BZ e EC duas diagonais paralelas ${ }^{45}$, e sendo ZF igual a $\mathrm{EF}$, e o triângulo ZLF igual ao triângulo QFE ${ }^{46}$, então o triângulo ZLF é a vigésima quarta parte de AG. E, sendo BH igual a EH, então o triângulo BEZ é o quadruplo do triângulo BHT, porque cada um deles tem ângulos retos, mas como o triângulo BEZ é um quarto de ABGD de lados paralelos, então o triângulo $\mathrm{BHT}^{47}$ é a décima sexta parte de ABGD de lados paralelos. Imaginemos uma linha $\mathrm{HK}$ traçada em direção ao ponto A; e sendo essa a sua situação, segue-se ${ }^{48}$, então, que $\mathrm{AB}$ está para $\mathrm{HT}$ assim como BK está para KT; mas $\mathrm{AB}$ é o dobro de TH e BK é o dobro de KT; consequentemente, BT é o triplo de KT e o triângulo BHT é o triplo do triângulo KHT. No entanto, o triângulo BHT é a décima sexta parte de ABGD de lados paralelos, como evidenciamos. Assim, o triângulo HTK $^{49}$ é a quadragésima oitava parte de ABGD; e o triângulo BKH é o dobro do triângulo THK ${ }^{50}$; então, o triângulo BKH é a vigésima quarta parte de ABGD. Ademais, a linha BL é o dobro da linha $Z^{51}$, e $A L$ é o dobro de $L F^{52}$, então o triângulo $A B L$ é o dobro do triângulo $A L Z$ e o triângulo ALZ é o dobro do triângulo ZLF ${ }^{53}$. No entanto, como o triângulo ZLF é a vigésima quarta parte de AG de lados paralelos, então o triângulo AZL é sua décima segunda parte. Resta que o triângulo ALB é a sexta parte de ABGD. Sendo os triângulos ABM e BML iguais ${ }^{54}$, cada um deles é igual à décima segunda parte de AG de lados paralelos. Resta que LTHEF de cinco lados é igual à metade da sexta parte e à metade da oitava parte da figura de lados paralelos como um todo ${ }^{55}$.

O quadrilátero AE, também, ficou dividido em sete partes; e, com efeito, a figura ABGD de lados paralelos como um todo ficou dividida em catorze partes, com relações que lhe são adequadas $^{56}$.

É isto que queríamos. Completou-se o livro de Arquimedes - Stomákhion - na segundafeira, dia 6 do mês de Rabi’ al-Awal do ano de $1041^{57}$.

\footnotetext{
${ }^{45}$ Cf. Euclides, Elementos, VI, 2.

${ }^{46}$ Cf. Euclides, Elementos, VI, 19.

${ }^{47}$ Aqui o tradutor/copista árabe parece ter cometido um deslize, escrevendo BET. Possivelmente a troca da letra grega $\mathrm{H}$ pela letra grega $\mathrm{E}$ se deve à semelhança dos fonemas representados por ambas.

${ }^{48}$ Cf. Euclides, Elementos, VI, 4.

${ }^{49}$ A variação da ordem das letras para designar este triângulo (KHT e HTK) está no texto árabe.

${ }^{50} \mathrm{Cf}$. Euclides, Elementos, VI, 1.

${ }^{51}$ Pela semelhança dos triângulos ABL e FZL, com os lados em razão 2:1.

${ }^{52}$ Ver a nota anterior.

${ }^{53}$ Cf. Euclides, Elementos, VI, 1.

${ }^{54} \mathrm{Cf}$. Euclides, Elementos, VI, 1. Observe-se que BF pode ser visto como a altura comum aos triângulos ABM e BML.

${ }^{55}$ Esta é a única figura cuja área em relação ao quadrado não é expressa como uma fração unitária, isto é, cujo denominador não é a unidade. No entanto, essa área é indicada como soma de frações desse tipo, equivalente à fração $\frac{\sqrt{5}}{2}$.

${ }^{56}$ Ver nota 32.

${ }^{57}$ Esta data do calendário islâmico corresponde a uma sexta-feira do dia 6 de março de 1632 do calendário da era cristã.
} 


\subsection{Notas filológicas}

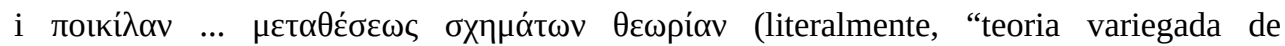

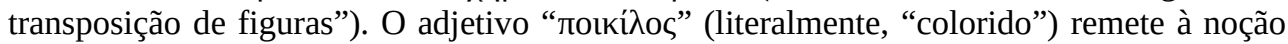
de "variedade/multiplicidade" ou de "complexidade". O problema que se coloca à leitura da passagem é o de saber qual é exatamente o sentido de theoría. Possuiria o termo um sentido

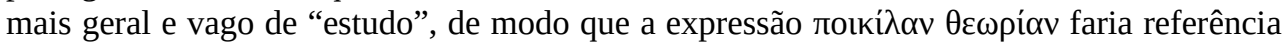
aos "vários estudos" existentes sobre o stomákhion, como se Arquimedes iniciasse o seu texto fazendo alusão ao "estado da questão" sobre o jogo? Ou deveria o termo ser entendido num sentido mais preciso e forte, como conhecimento dos princípios matemáticos que

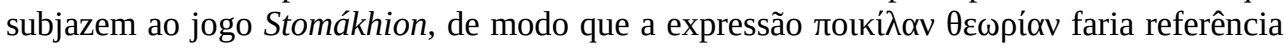
à teoria arquimediana elaborada no tratado? Esse último sentido parece ser o mais provável, por duas razões: Arquimedes não faz qualquer menção a outros estudos sobre o jogo (ao menos aqui no início de seu tratado, onde seria o lugar mais apropriado); não há notícia de que haja outro tratamento matemático do Stomákhion. Além disso, o uso do verbo ékho (ter, conter) talvez seja significativo: o Stomákhion contém (žxovtoৎ) a teoria que, nele latente, será exposta por Arquimedes: é preciso inspecioná-lo, contemplá-lo, observá-lo para descobri-la. Mas, então, como entender o adjetivo поккí $\alpha$ $\alpha$ ? Deixando de lado a noção de "variedade", porque a teoria seria uma só, a tradução mais rente ao original seria "teoria complexa/intrincada da transposição". No entanto, uma vez que o problema matemático apresentado pelo Stomákhion consiste justamente no grande número de diferentes disposições das peças (figuras) que montam o quadrado, o adjetivo “локкі́ referência, não à complexidade da teoria, mas sim à multiplicidade das possíveis transposições das figuras. Arquimedes teria, portanto, empregado uma hipálage. Desfazendo essa figura de linguagem para tornar o texto mais preciso, alenta-se também a possibilidade de uma tradução não literal: "teoria da múltipla transposição das figuras".

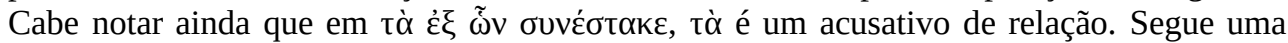

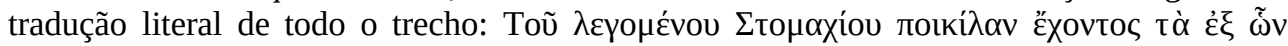

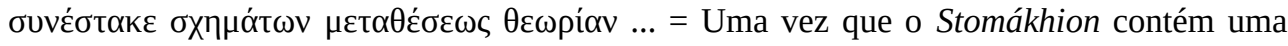
teoria intrincada de uma transposição de figuras com relação àquelas [figuras] de que ele se

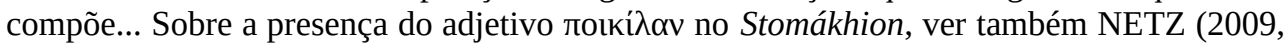
p. 136).

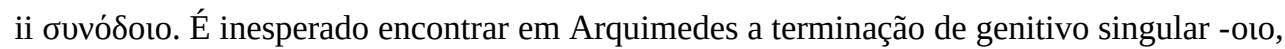

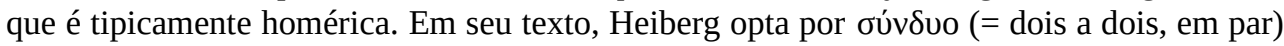

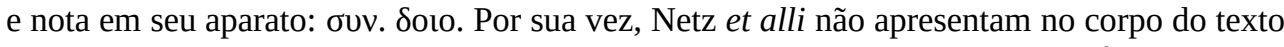
qualquer indicação de que o trecho estaria corrompido, mas em seu aparato, além de indicar

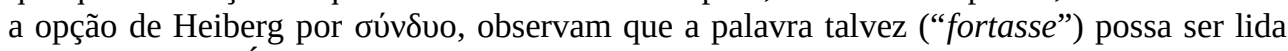

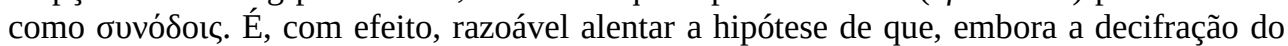
palimpsesto estabeleça com segurança a forma ouvódoı,o, o copista tenha errado ao escrever -oıo em lugar de -oıc (= -oıৎ). Do ponto de vista do sentido do texto, porém, não há

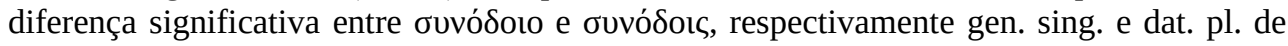

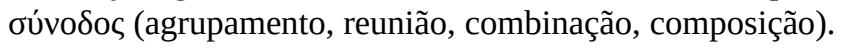


iii Literalmente, Ėvó́nopбıৎ significa encaixe, ajuste. Segundo o léxico de Mugler (ver MUGLER, 1958), trata-se da operação de "encaixar um segmento de linha dentro de uma figura, círculo, ângulo etc.” Optamos por traduzir o termo por composição para deixar o argumento mais claro em português. A operação de "encaixe" aqui nomeada consiste em compor dois ou mais ângulos para formar dois retos.

iv A expressão tõ̃ $\theta \varepsilon \omega p i ́ \alpha$ l $\lambda \alpha v \theta$ óvouoıv ("ainda que isso passe despercebido à observação") é de grande interesse para a discussão sobre a importância da física para a matemática arquimediana (debate que aparece também na interpretação da "Lei da Alavanca” e nos cálculos matemáticos de centro de gravidade no Método - ver, por

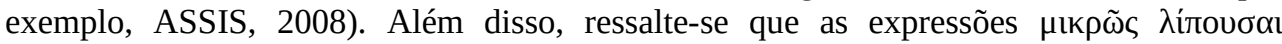

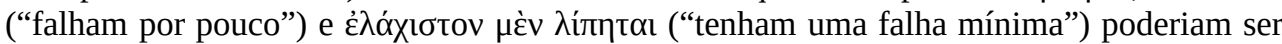
evocadas em relação às discussões sobre quantidades "negligenciáveis" em cálculos de áreas ou volumes - o que alguns comentadores entenderam ser uma antecipação de métodos de indivisíveis já no Método arquimediano (ver, por exemplo, KNORR, 1996).

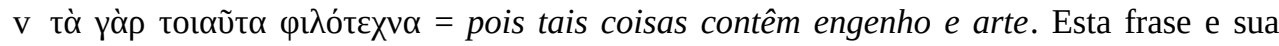
tradução merecem comentário. $\mathrm{O}$ adjetivo $\varphi \iota \lambda$ te $\chi v o \varsigma$ tem dois significados: 1.

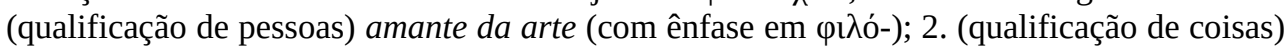

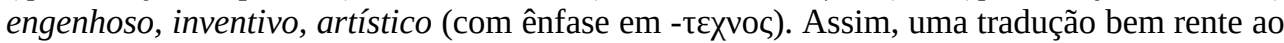
original seria: "pois coisas desse tipo [cálculos matemáticos] são engenhosas". A frase apresenta um argumento muito simples, mas de forte efeito retórico e amplo alcance teórico, ao fazer referência à expertise específica do matemático, àquilo que distingue seu saber e sua prática. A presente tradução se vale da célebre expressão de Camões "engenho e arte” (cunhada por influência do Renascimento italiano), não só porque tal expressão

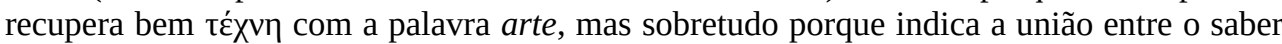
e a inventividade, sendo precisamente esse o ponto de Arquimedes. A tradução de Netz et alli segue essa mesma linha interpretativa: "For such considerations as these are intellectually challenging". Em nota, comenta o estudioso israelense: "An anachronistic rendering of philotechna, "<worthy of $>$ the love of art" (ver NETZ, ACERBI \& WILSON, 2004, p. 74).

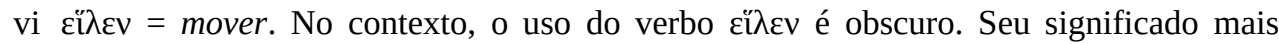
preciso é rolar. Por extensão, pode significar também girar e esmagar (no sentido de "rolar sobre algo"). Netz et alli o traduzem por rotate, comentando em nota: "A tradução de uma única e crucial palavra é difícil quando tal palavra dificilmente dá sentido à leitura e é provavelmente corrupta." (ver NETZ, ACERBI \& WILSON, 2004, p. 74, n. 21). De todo modo, no presente contexto, é bem plausível que o verbo se refira aos movimentos pelos quais as peças do stomákhion trocam de posição. Nesse sentido, na frase "mover um mesmo lugar para outro", a palavra "lugar” não nomeia uma posição fixa no espaço, mas sim uma forma geométrica que pode ocupar diferentes posições em diferentes configurações do quadrado (tal como as peças do jogo). 
vii Heiberg traduz $\theta \varepsilon \dot{\rho} \eta \mu \alpha$ por propositio no Stomákhion, ainda que tenha preferido manter o decalque latino theorema ao traduzir o mesmo termo em outras ocorrências, como na Quadratura da Parábola. A tradução apresentada opta por teorema por duas razões: 1. o termo alude à noção de teoria presente nas primeiras linhas do tratado (ver acima nota i e ARQUIMEDES, 1910-15, Vol. II, p. 419); 2. o termo faz referência a um enunciado com as características de um teorema: uma afirmação que não é autoevidente, validada por uma demonstração. 


\section{Textos originais}

6.1 Texto grego original (NETZ, ACERBI \& WILSON, 2004)

$\mathrm{H}: 416$

APXIMH $\Delta$ O $\Sigma \Sigma T O M A$

177r. col. 2

..... ON

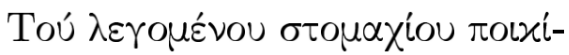

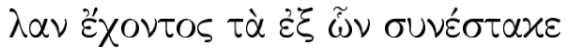

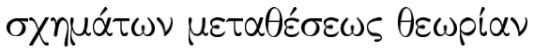

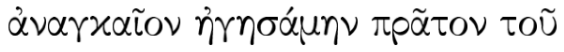

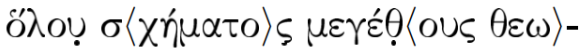

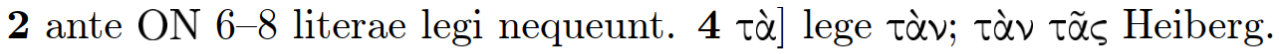

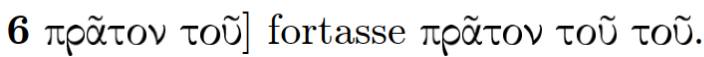

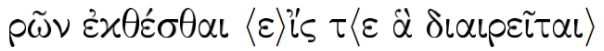

172v. col. 2

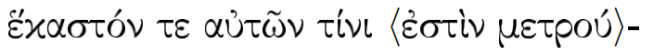

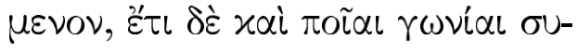

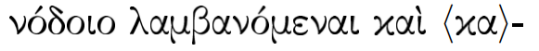

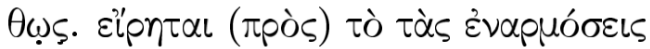

5

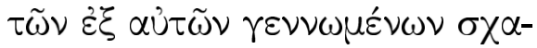

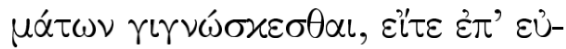

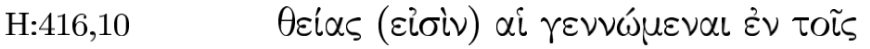

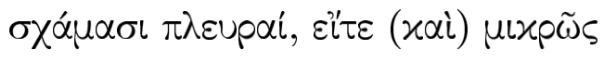

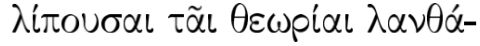

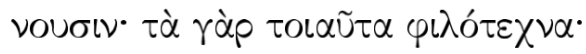

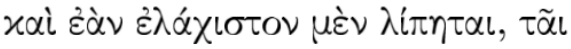

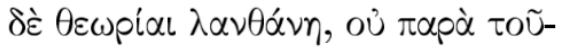

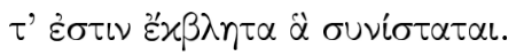

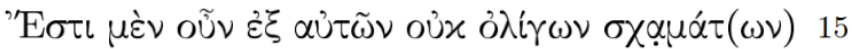




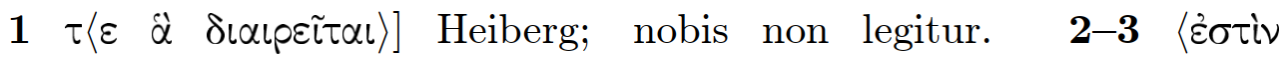

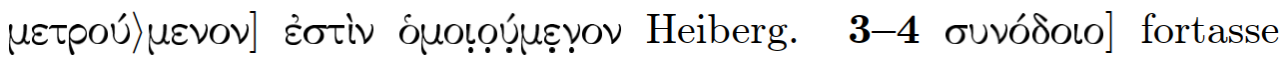

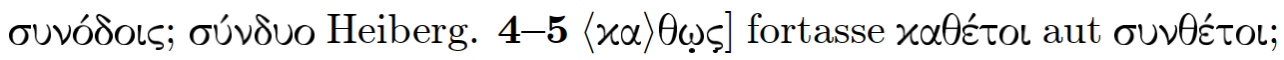

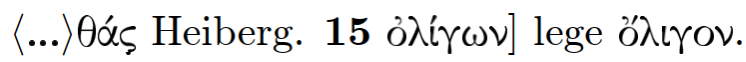

$\mathrm{H}: 416,20$

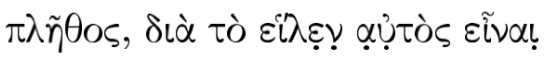

177v. col. 1

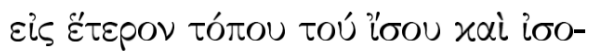

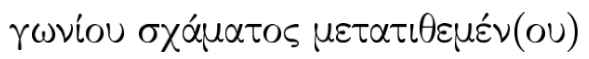

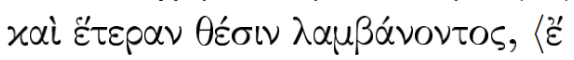

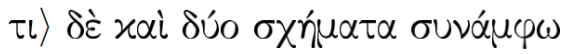
5

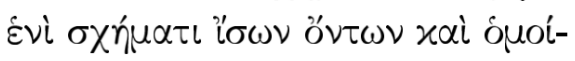

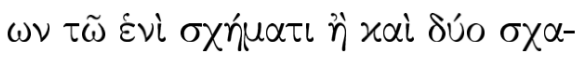

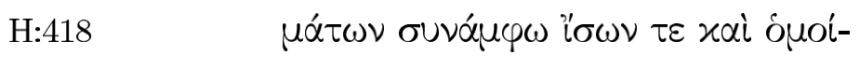

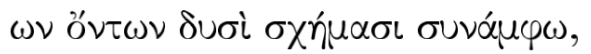

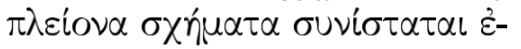

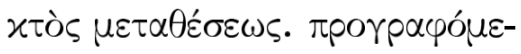

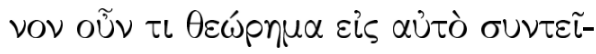

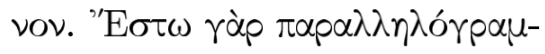

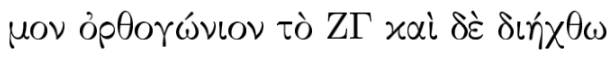

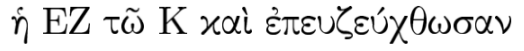

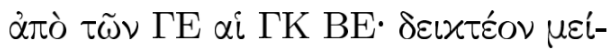

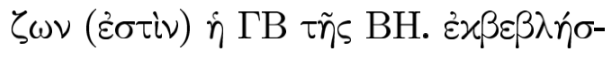

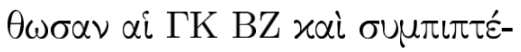

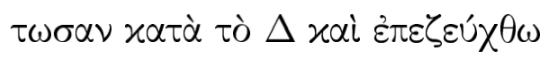

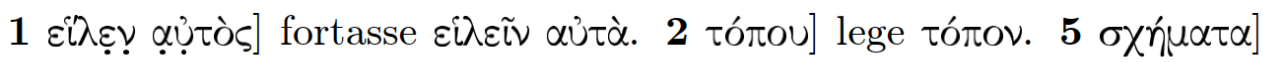

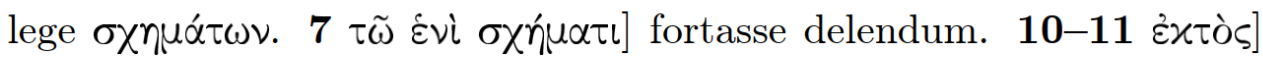

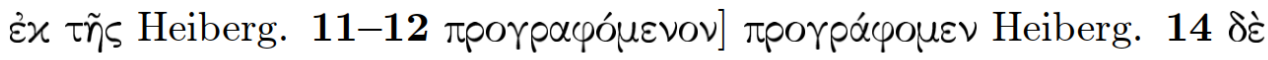
$\delta\llcorner\dot{n} \chi \theta \omega]$ requiritur $\delta i \chi \chi \alpha \tau \varepsilon \tau \mu \tilde{\gamma} \sigma \theta \omega$. 
H:418,10

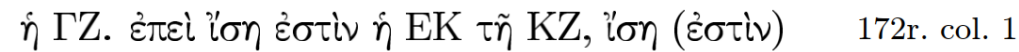

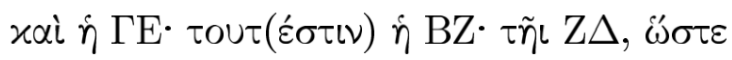

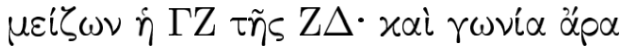

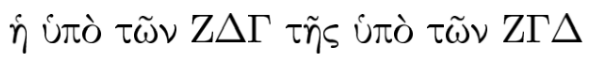

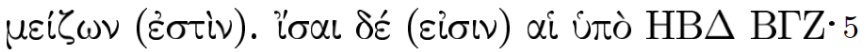

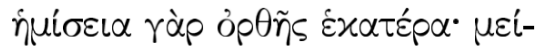

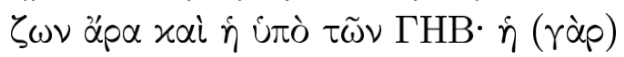

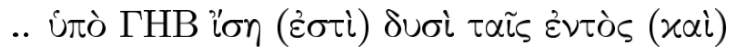

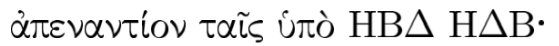

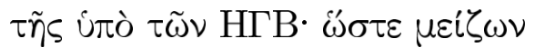

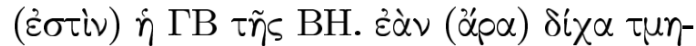

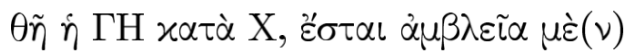

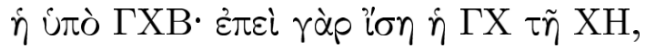

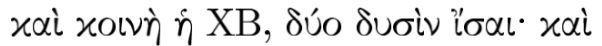

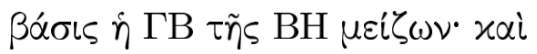

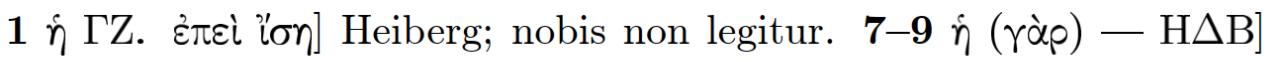

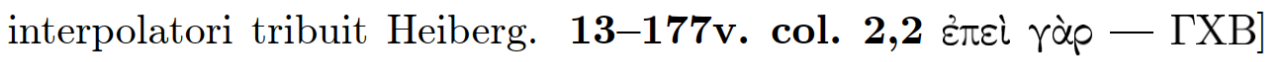
interpolatori tribuit Heiberg.

$\mathrm{H}: 418,20$

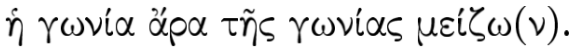

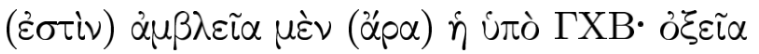

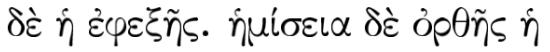

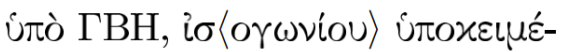

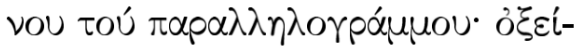

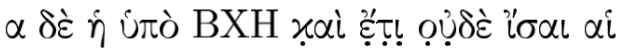

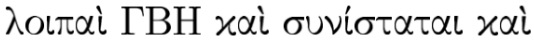

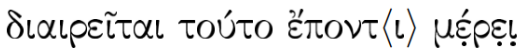$$
\text { 177v. col. } 2
$$$$
5
$$ 


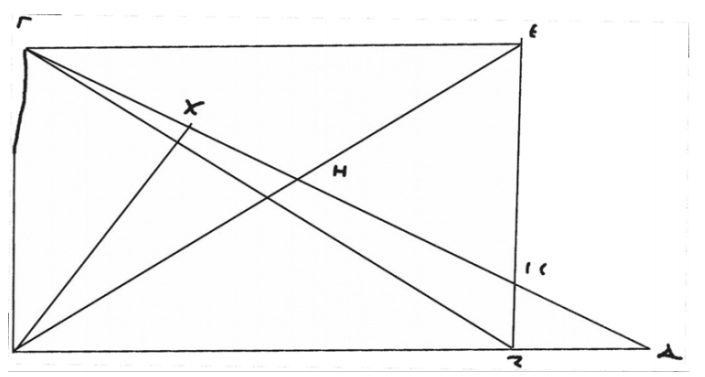

H:420

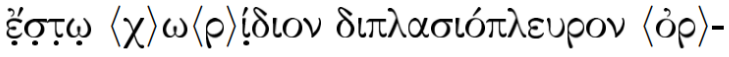

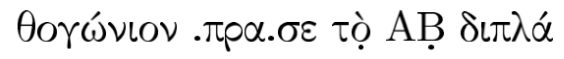

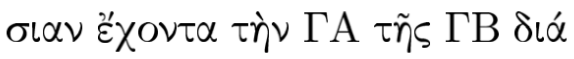

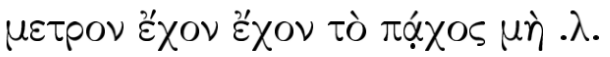

....... $\alpha \theta$

$\alpha$

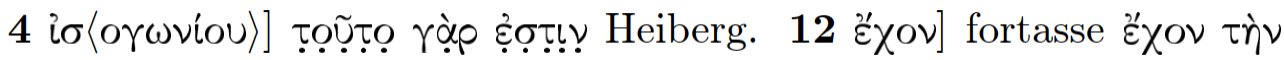
AB. 13 ante $\alpha \theta$ 6-8 literae legi nequeunt. post $\alpha \theta$ aliquot verba legi nequeunt.

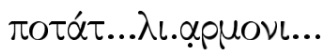

172r. col. 2

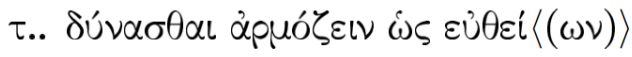

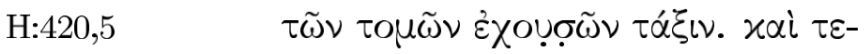

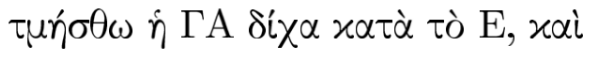

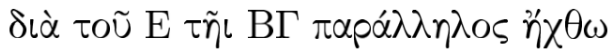

5

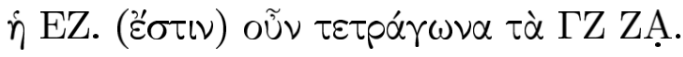

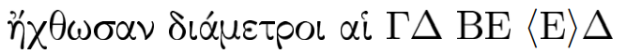

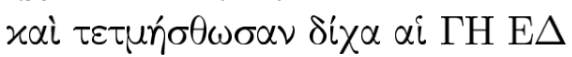

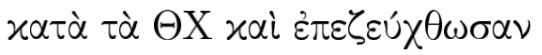

H:420,10

ai $\mathrm{B} \Theta \mathrm{XZ}$, xaì $\delta i \grave{\alpha} \tau \tilde{\omega} \nu\langle\mathrm{X}\rangle \mathrm{K} \tau \tilde{\eta} \mathrm{B} \Delta \pi \alpha-$

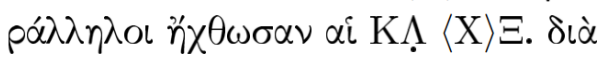

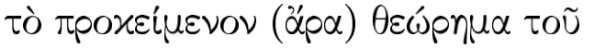

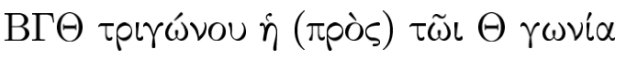

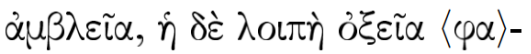

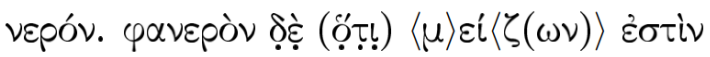




\subsection{Texto árabe original (SUTER, 1899)}

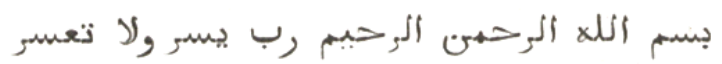

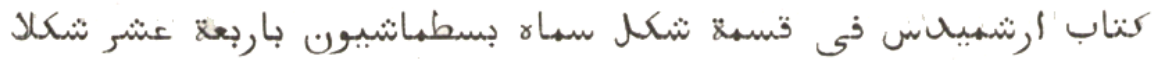

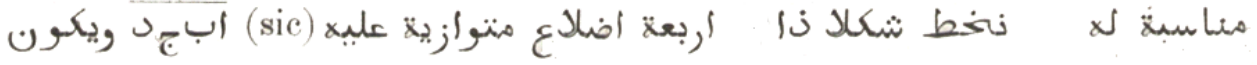

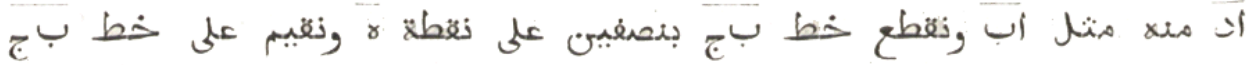

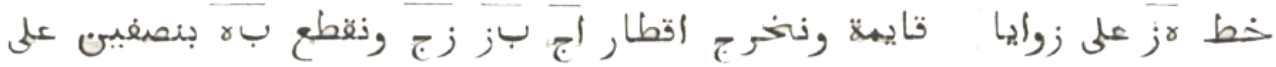

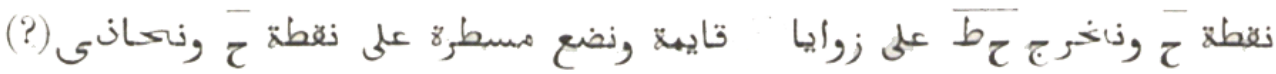

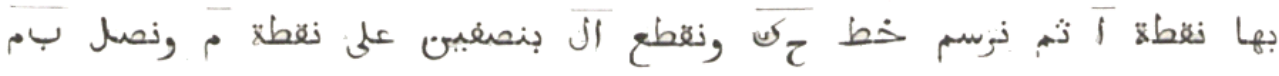

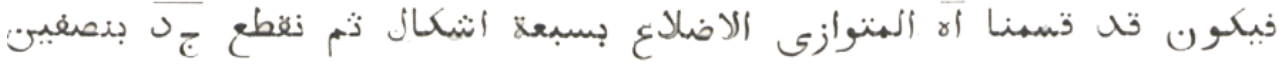

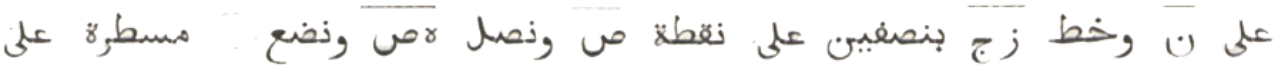

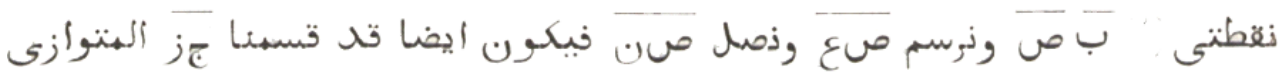
اللاضلاع بسبعة انشكان اختر ويكون جميبع الهنوازى الاضلاع النهى عليه

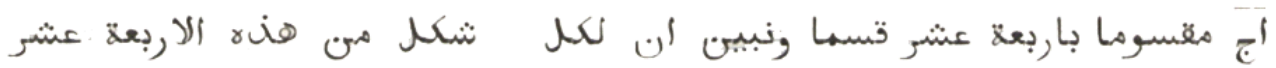

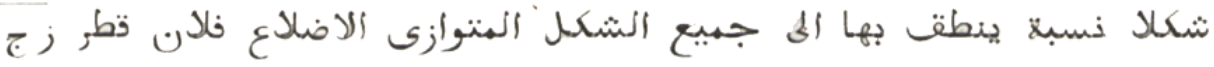

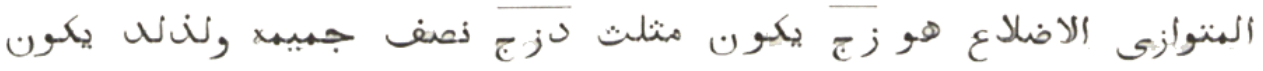

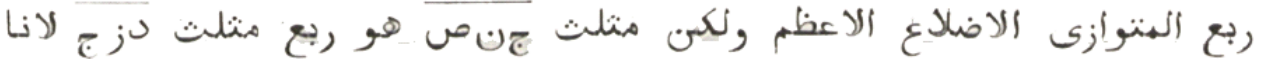

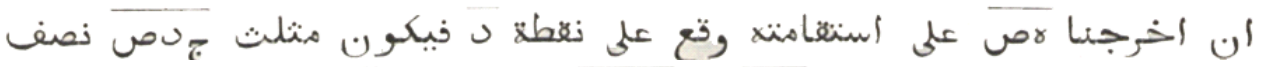

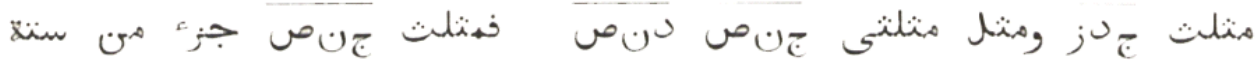

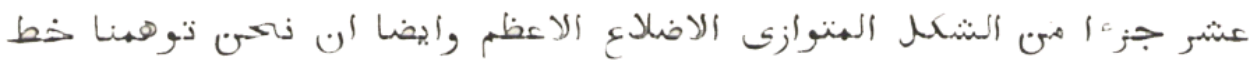

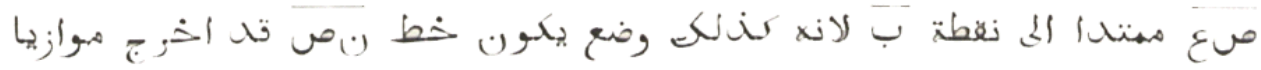

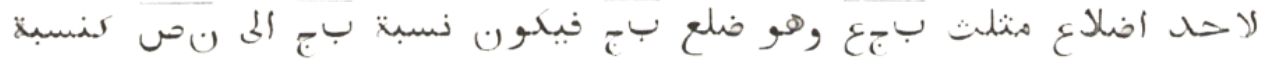

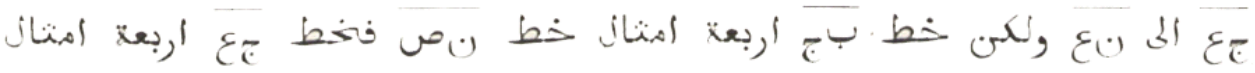

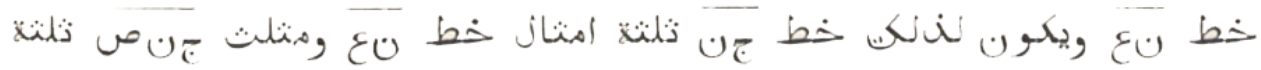

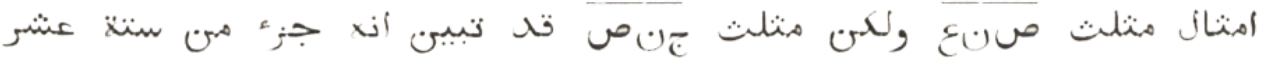

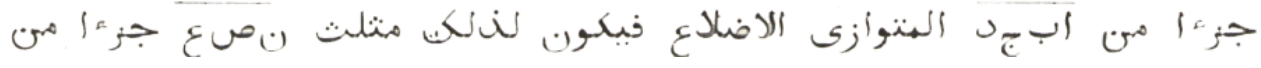




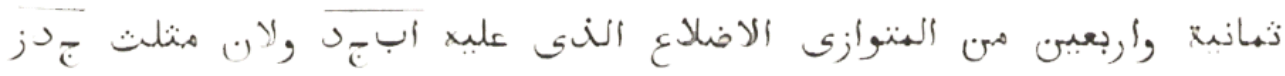

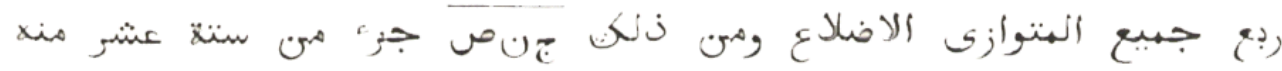

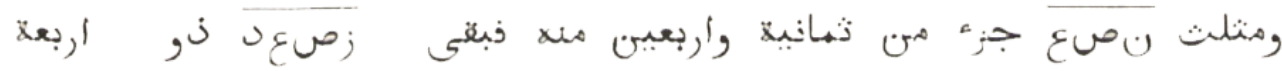

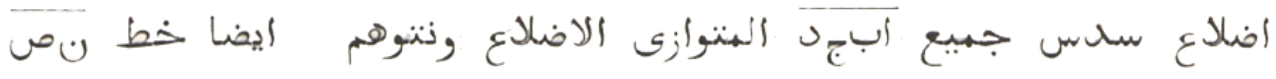

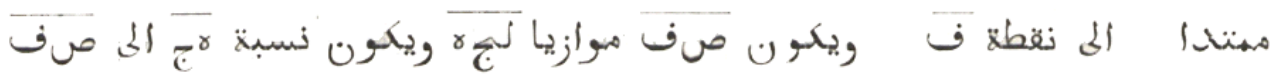

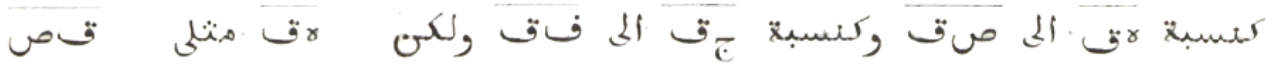

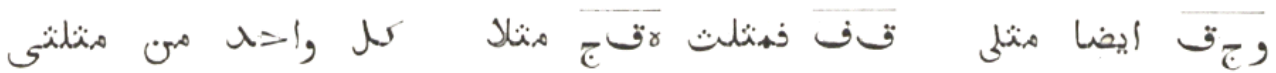

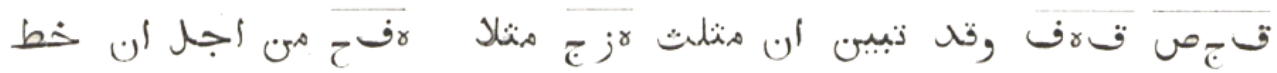

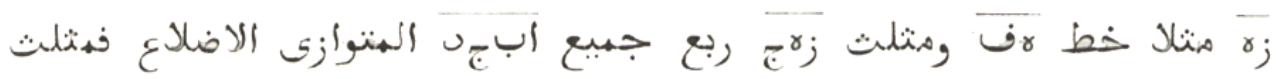

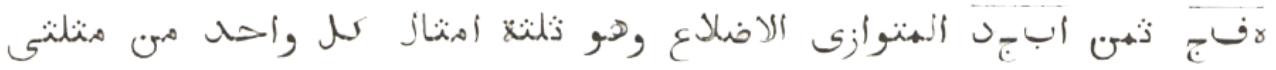

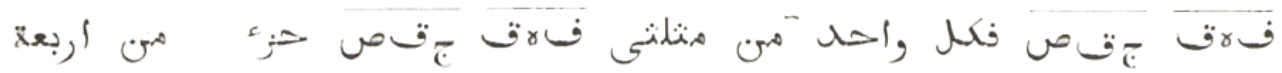

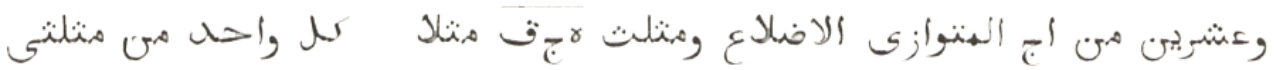

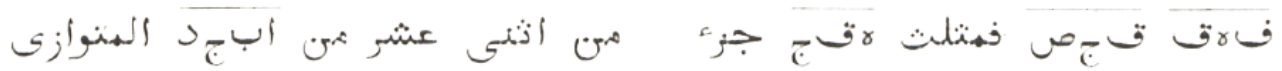

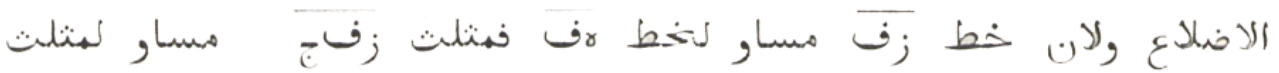

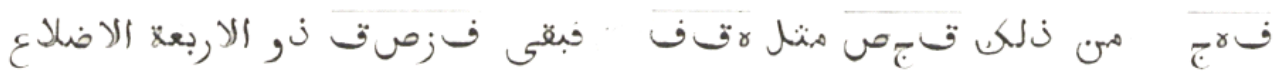

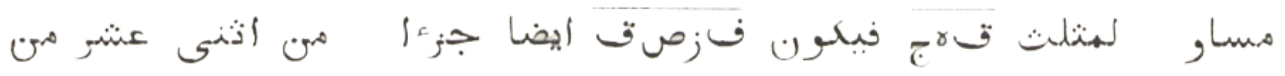

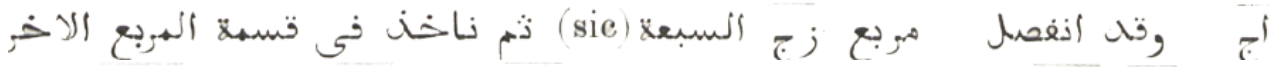

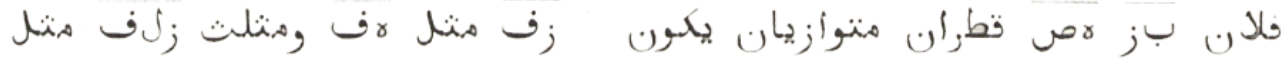

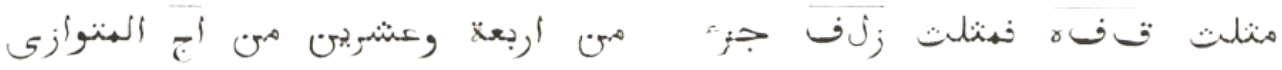

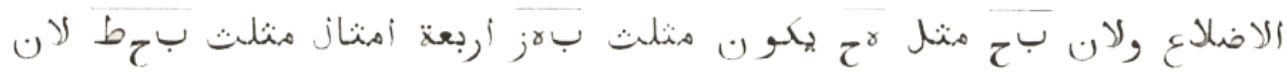

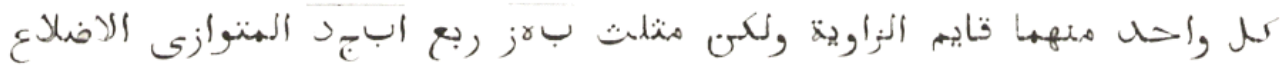




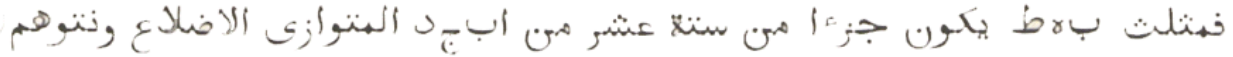

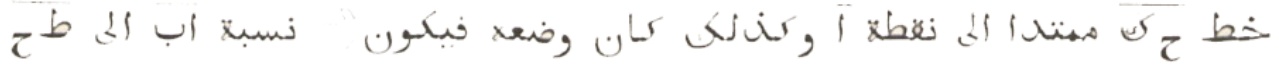

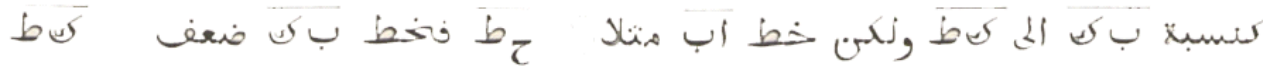
|فخغ بط |

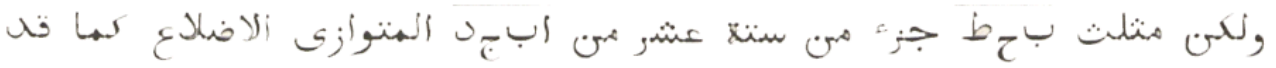

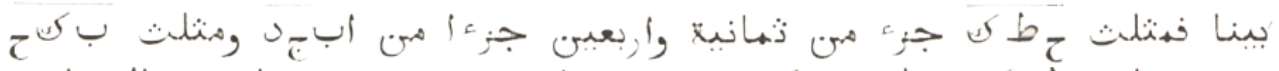

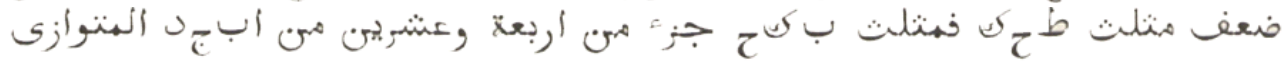

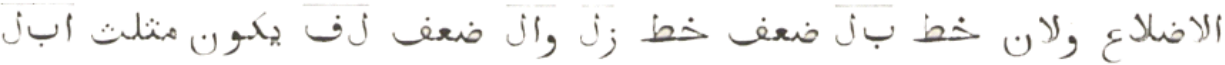

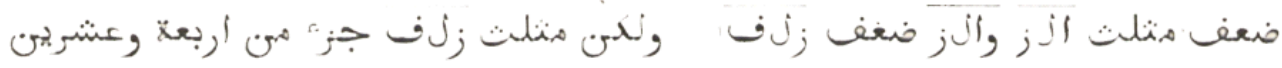

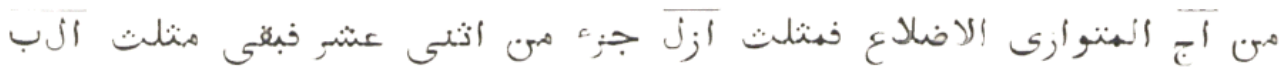

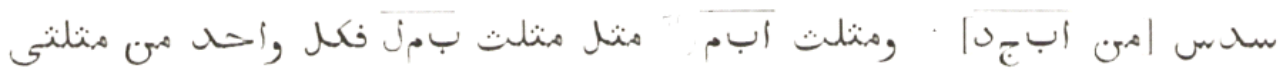

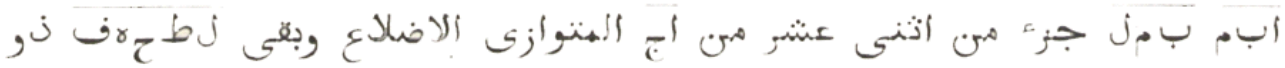

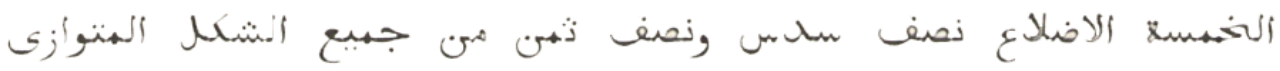

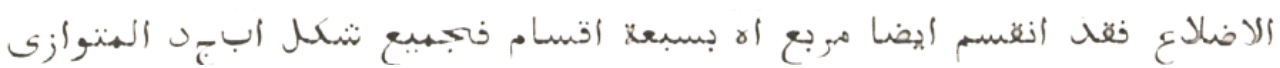

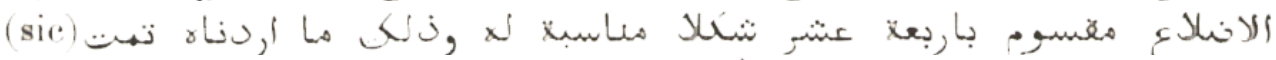

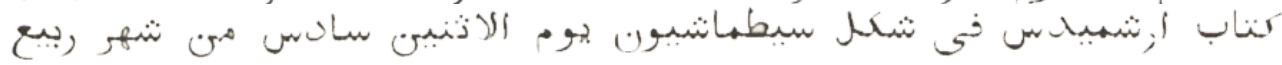
- 1.41 in
\end{abstract}

